\title{
Autophagy is involved in T cell death after binding of HIV-1 envelope proteins to CXCR4
}

\author{
Lucile Espert, ${ }^{1}$ Mélanie Denizot, ${ }^{1}$ Marina Grimaldi,, ${ }^{1}$ Véronique Robert-Hebmann, ${ }^{1}$ \\ Bernard Gay, ${ }^{1}$ Mihayl Varbanov,1 Patrice Codogno,,2 and Martine Biard-Piechaczyk'
}

1'Laboratoire Infections Rétrovirales et Signalisation Cellulaire, CNRS UMR 5121, Institut de Biologie, Montpellier, France. 2INSERM U504, Villejuif, France.

\begin{abstract}
HIV-1 envelope glycoproteins (Env), expressed at the cell surface, induce apoptosis of uninfected CD4 ${ }^{+} \mathrm{T}$ cells, contributing to the development of AIDS. Here we demonstrate that, independently of HIV replication, transfected or HIV-infected cells that express Env induced autophagy and accumulation of Beclin 1 in uninfected CD4 ${ }^{+} \mathrm{T}$ lymphocytes via CXCR4. The same phenomena occurred in a $\mathrm{T}$ cell line and in transfected HEK.293 cells that expressed both wild-type CXCR4 and a truncated form of CD4 that is unable to bind the lymphocyte-specific protein kinase Lck. Env-mediated autophagy is required to trigger $\mathrm{CD}^{+} \mathrm{T}_{\text {cell apopto- }}$ sis since blockade of autophagy at different steps, by either drugs (3-methyladenine and bafilomycin A1) or siRNAs specific for Beclin 1/Atg6 and Atg7 genes, totally inhibited the apoptotic process. Furthermore, $\mathrm{CD}^{+} \mathrm{T}$ cells still underwent Env-mediated cell death with autophagic features when apoptosis was inhibited. These results suggest that HIV-infected cells can induce autophagy in bystander CD4 ${ }^{+} \mathrm{T}$ lymphocytes through contact of Env with CXCR4, leading to apoptotic cell death, a mechanism most likely contributing to immunodeficiency.
\end{abstract}

\section{Introduction}

The development of AIDS in HIV-infected patients is characterized by a progressive decline in the number of $\mathrm{CD} 4^{+} \mathrm{T}$ cells. Although the multiple mechanisms that lead to this demise of CD4 ${ }^{+} \mathrm{T}$ cells have yet to be fully elucidated, virus-induced programmed cell death (PCD) of uninfected $\mathrm{CD}^{+} \mathrm{T}$ lymphocytes clearly contributes to this phenomenon (1-3). In particular, bystander $\mathrm{CD}^{+} \mathrm{T}$ cell death induced by HIV-1 envelope glycoproteins (Env) gp120 and gp141 expressed on infected cells is one of the processes linked to immunodeficiency. These contacts between infected and uninfected cells, which occur in epithelia and lymphoid tissues, are important for HIV transmission (4-7). We and others have demonstrated that cells that express CXCR4-using HIV-1 isolates (X4) Env (either Envtransfected cells; refs. 8, 9; or infected cells; ref. 10) trigger uninfected $\mathrm{CD}^{+} \mathrm{T}$ cell apoptosis. The CXCR4/Env interaction plays a central role in this phenomenon by inducing an apoptotic pathway that involves mitochondrial transmembrane depolarization and caspase- 3 activation independently of Fas-mediated signaling and $G_{i}$ protein activation (9). This mechanism may explain the $T$ cell drop that often coincides with the emergence of X4 isolates during the later stages of the disease. As CXCR4 is primarily expressed on cells with a resting naive phenotype, $\mathrm{X} 4$ variants were therefore suggested to exercise their harmful effects through enhanced killing of uninfected naive $\mathrm{CD}^{+} \mathrm{T}$ cells (11). Massive elimination of naive CXCR4 ${ }^{+}$ $\mathrm{CD}^{+} \mathrm{T}$ cells has also been observed in highly pathogenic simian/ human immunodeficiency virus-infected rhesus monkeys (12).

Although PCD can manifest itself in many forms, 2 major types have been described: type I PCD, or apoptosis, and type II PCD, also called autophagic cell death, which is characterized by the

Nonstandard abbreviations used: Baf A1, bafilomycin A1; Env, HIV-1 envelope glycoproteins; GFP-LC3, LC3 fused to GFP; LC3, light chain 3; 3-MA, 3-methyladenine; PCD, programmed cell death; PI, propidium iodide; Rapa, rapamycin; TEM, transmission electron microscopy; UC, umbilical cord; X4, CXCR4-using HIV-1 isolates; z-VAD, z-Val-Ala-Asp (OMe)- $\mathrm{CH}_{2} \mathrm{~F}$.

Conflict of interest: The authors have declared that no conflict of interest exists. Citation for this article: J. Clin. Invest. 116:2161-2172 (2006). doi:10.1172/JCI26185. accumulation of autophagic vacuoles and the absence of caspase activation (13-15). However, cell death - characterized by hallmarks of both type I PCD and type II PCD - is frequently observed, making a clear-cut difference between them difficult $(16,17)$.

Macroautophagy, herein referred to as autophagy, is a major lysosomal catabolic pathway for cytoplasmic macromolecules and organelles (18). This process is characterized by the formation of double or multiple membrane-bound autophagosomes that engulf cytoplasmic material. After maturation, autophagosomes fuse with lysosomes to digest the sequestered material. Autophagy, first discovered to occur in yeast, is a highly regulated physiological process mediated by 2 conjugation systems related to ubiquitylation. Both systems depend on Atg proteins and their related signaling pathways $(19,20)$. In the first conjugation system, Atg12 is activated by the E1-like enzyme Atg7, transferred to the E2-like enzyme Atg10, and finally conjugated to Atg5 to form an autophagosomal precursor (21). In the second conjugation system, Atg8 is activated by Atg7, transferred to Atg3, another E2-like enzyme, and finally conjugated to phosphatidyl ethanolamine. Thus, Atg7 is essential for activation of these 2 conjugation systems and, consequently, for the autophagic process (21). Microtubule-associated protein 1 light chain 3 (LC3) is the mammalian ortholog of Atg8 and was the first identified on the autophagosome membrane (22). Class III PI3K is involved in the early stages of autophagic vesicle formation and controls the autophagic pathway through its association with Beclin 1, the ortholog of yeast $\operatorname{Atg} 6(23,24)$.

Autophagy is a cell survival mechanism during nutrient starvation $(25,26)$ that supplies vital components until conditions improve. Moreover, starvation-induced autophagy protects cells from the induction of apoptosis (27). However, several recent studies have shown that cell death can be blocked after knockdown of autophagy genes (28-30). These results give credence to the role of autophagy as a cell death process (for review see refs. 31-33). Recent data also indicate that a connection exists between pathways that regulate autophagy and apoptosis. Indeed, several molecules such as Bcl-2 family proteins (28, 29, 


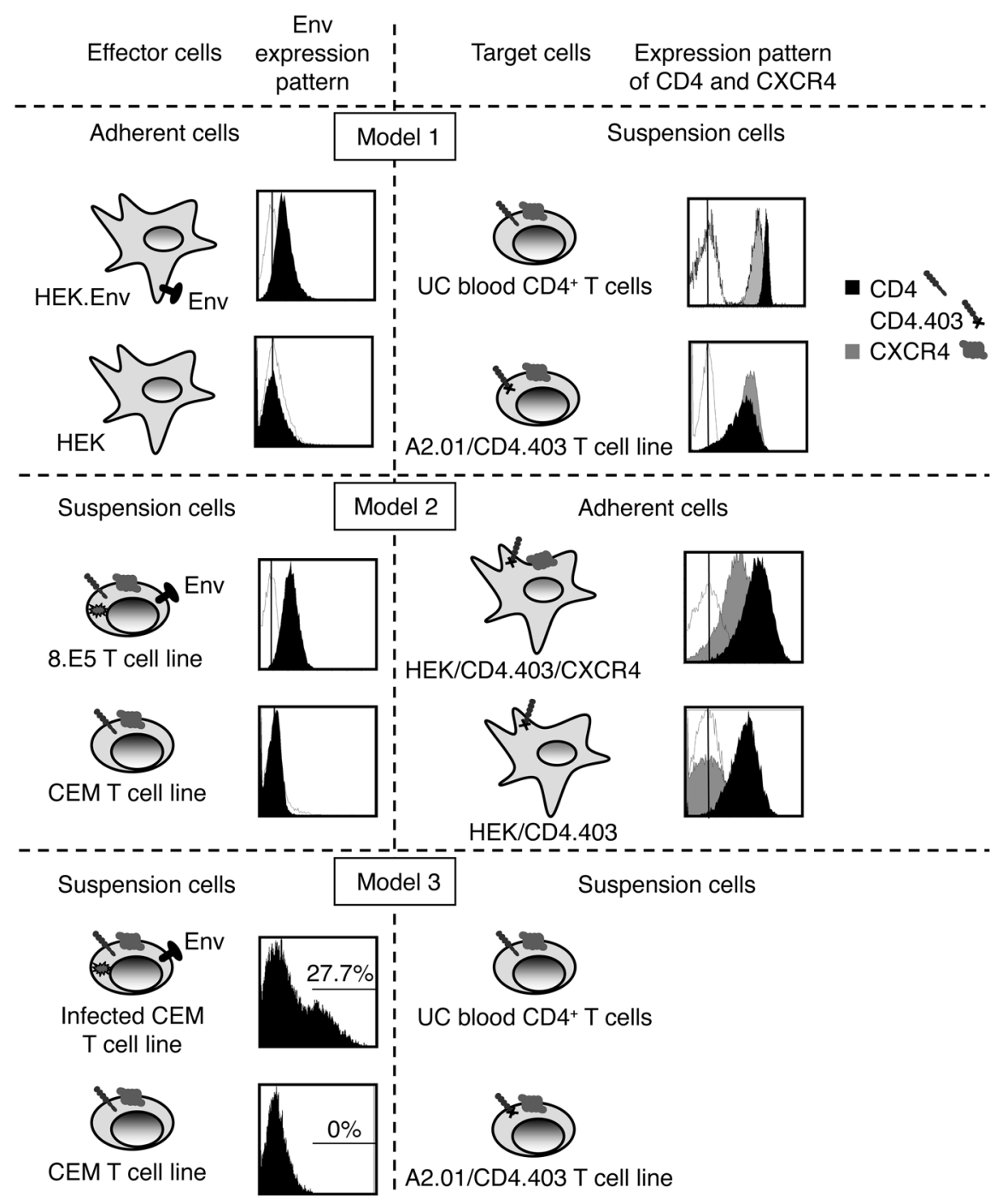

Figure 1

Description of the cellular models. In model 1 , target $C D 4+T$ cells $(U C$ blood CD4+ $T$ cells and a $T$ cell line expressing CXCR 4 and CD4.403) are cocultured with effector HEK cells with or without Env expression. In model 2, HEK/CD4.403/CXCR4 and HEK/ CD4.403 cells are cocultured with effector $\mathrm{T}$ cells with or without Env expression. In model 3 , target $C D 4+T$ cells are cocultured

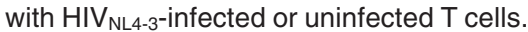
Expression of gp120 at the surface of HEK. Env, 8.E5, and HIV $\mathrm{NL4-3}_{\text {-infected effector }}$ cells as well as parental HEK and CEM cells - used as negative controls - were analyzed by flow cytometry after incubation of the cells with PBS (white histograms) or with PBS containing anti-gp120 human polyclonal Ab (black histograms). Bound $A b$ was detected with a secondary FITClabeled goat anti-human Ig. Expression analysis of the extracellular domains of CD4 and CXCR4 at the surface of target cells was performed after incubation of the cells with PBS (white histograms) or with anti-CD4 (black histograms) or anti-CXCR4 (gray histograms) $\mathrm{mAb}$ at $10 \mu \mathrm{g} / \mathrm{ml}$. Bound $\mathrm{mAb}$ was detected with FITC-labeled goat anti-mouse Ig. The fluorescence intensity was recorded in the log mode on an EPICS XL4 cytofluorometer.
$34)$, the Bcl-2-interacting protein Beclin 1 (28, 35-37), caspase- 8 (38) and caspase-9 (35), PI3K class I (39-41), and the sphingolipid ceramide $(42,43)$ are involved in the control of both apoptosis and autophagy.

Autophagy is triggered in different infections, and several bacteria and viruses have evolved strategies to use components of the autophagic pathway to facilitate their own replication (44-46). Its induction has been observed in response to infection by herpes simplex virus (47), coronavirus (45), and poliovirus $(46,48,49)$. Autophagy, in this case named xenophagy, has also been described as a component of the innate immune response that degrades intracellular pathogens (50). This process has also been shown to lead to endogenous MHC class II processing of an Epstein-Barr viral nuclear antigen (51). These data demonstrate that interactions exist between the autophagic pathway and the infectious cycles of several viruses. However, to our knowledge, the occurrence of autophagy has not previously been demonstrated in HIV infection, and there are no descriptions of a putative role of autophagy in cell death induced after viral infection.

On the basis of the hypothesis that HIV-induced bystander naive $\mathrm{CD}^{+} \mathrm{T}$ cell killing is central to immunodeficiency, we investigated whether X4 Env is able to trigger autophagy in $\mathrm{CD} 4^{+} \mathrm{CXCR} 4^{+}$ uninfected cells under the conditions known to induce apoptosis. We demonstrate here that cell-expressed Env binding to CXCR4 induced autophagy of uninfected $\mathrm{CD}^{+} \mathrm{T}$ cells and that this was necessary for the induction of apoptosis.

\section{Results}

Cellular coculture models. Three models (Figure 1) were used to analyze the capacity of Env expressed on cells to trigger autophagy in the absence of viral replication. All 3 are based on the coculture of effector cells, which express Env, with target cells that express CD4 and CXCR4. These models were created to study the different putative situations in vivo, i.e., the interaction between adherent $\mathrm{HIV}^{+}$ epithelial cells and uninfected $\mathrm{CD} 4^{+} \mathrm{T}$ cells, or infected $\mathrm{T}$ cells and uninfected $\mathrm{CD}^{+} \mathrm{T}$ lymphocytes.

As naive $\mathrm{CD}^{+} \mathrm{T}$ cells are the main target of HIV-mediated apoptosis, purified primary umbilical cord (UC) blood CD4 $4^{+} \mathrm{T}$ lymphocytes, which constitute a homogeneous population of cells with a naive phenotype and a high number of CXCR4 molecules, were used in this study. Furthermore, target cells that express a truncated form of CD4 (CD4.403) capable of binding to gp120 but unable to transduce a signal via the lymphocyte-specific protein kinase Lck $(52,53)$ as well as target cells that express both CD4.403 

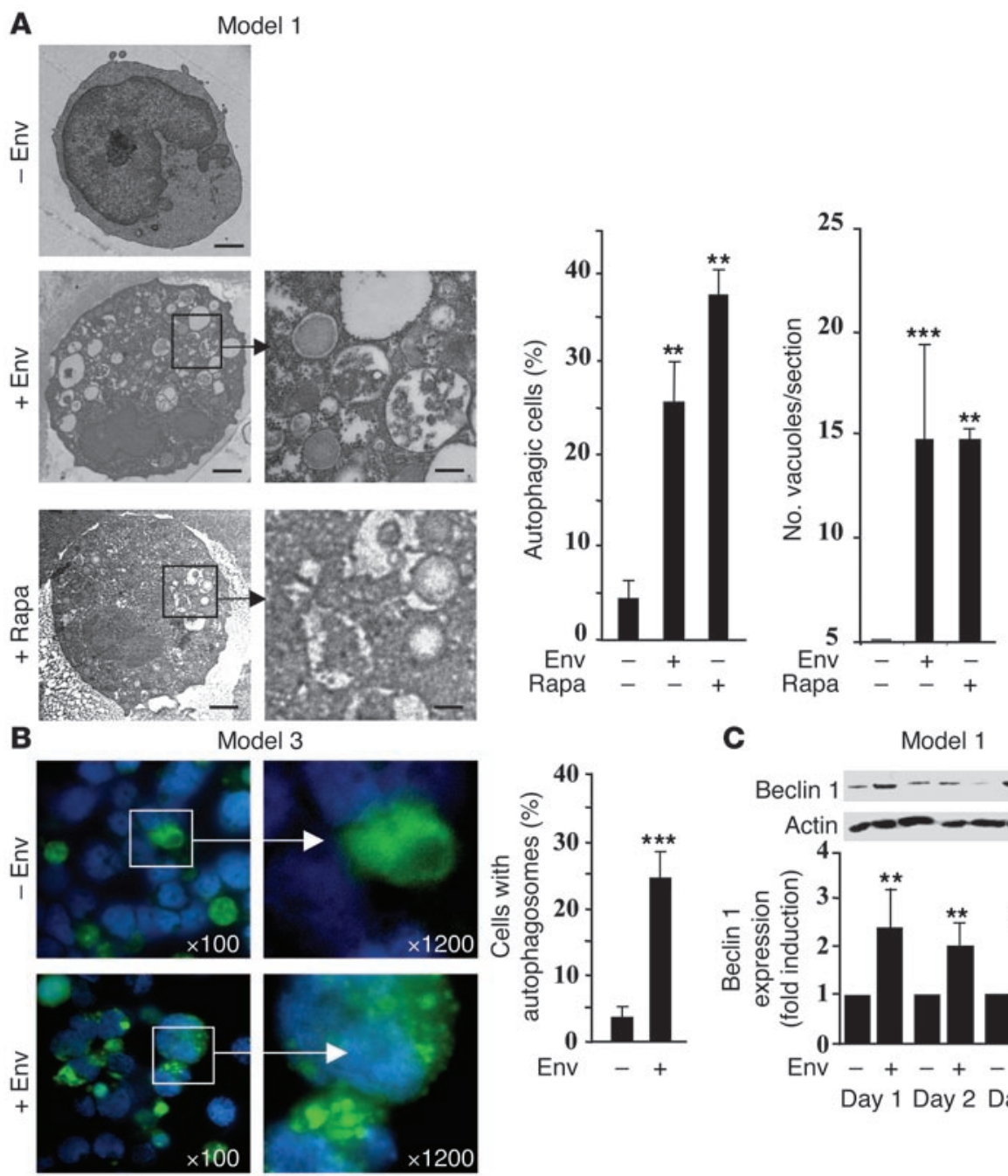

C

Model 1

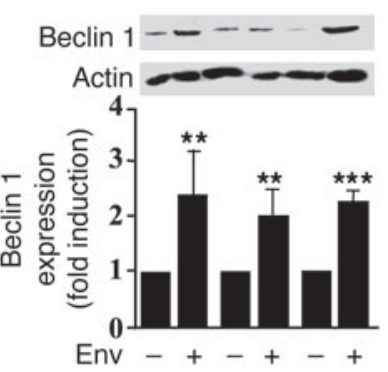

Day 1 Day 2 Day 3

Figure 2

Autophagy is induced by cell-expressed Env, and Beclin 1 is accumulated during this process. (A) UC blood CD4+ $\mathrm{T}$ lymphocytes were purified by negative selection using the CD4+ Rosette separation technique. Cells were cocultured for 3 days with HEK or HEK.Env or treated with $1 \mu \mathrm{M}$ Rapa and examined by TEM. Autophagic (vacuolated) cells were defined as cells that had 5 or more autophagic vacuoles. The percentage of autophagic cells and the number of vacuoles in the target cell sections were analyzed from at least 100 randomly chosen TEM fields by 2 investigators. Scale bars: 1 um; $250 \mathrm{~nm}$ (indicated enlargements). (B) UC blood CD4+ T cells were transfected with GFP-LC3, cocultured with HIV $_{\mathrm{NL4-3}}$-infected or uninfected CEM cells, and examined by epifluorescence. Data are representative of 3 independent experiments; more than 100 cells were counted by 2 investigators. Cells with autophagosomes were defined as cells that had 5 or more LC3 spots in the cytoplasm. Magnification shown. (C) Beclin 1 expression was analyzed in UC blood CD4 ${ }^{+} \mathrm{T}$ cells cocultured with effector HEK cells with or without Env expression. Fold induction was calculated as the intensity of the Beclin 1 immunoblot obtained in cells cocultured with effector cells expressing Env compared with effector cells that do not express Env. Ratios were normalized to that obtained with anti-actin Ab. Data are representative of at least 3 independent experiments. ${ }^{* \star} P<0.01 ;{ }^{* \star *} P<0.001$.

and wild-type CXCR4 were also analyzed to determine the role of these receptors in Env-mediated autophagy.

In model 1, the target cells (in which autophagy was analyzed) were either $\mathrm{CD}^{+} \mathrm{T}$ lymphocytes or the A2.01/CD4.403 T cell line, which expresses wild-type CXCR 4 and CD4.403. These target cells were cocultured with effector HEK.293 cells that stably express Env (HEK.Env). The parental HEK cell line was used as a negative control. This model has previously been used to analyze
Env-mediated apoptosis triggered in $\mathrm{CD}^{+} \mathrm{T}$ cells $(9)$.

In model 2, the target cells were stably transfected HEK cells that express CD4.403 (HEK/CD4.403) or CD4.403 and CXCR4 receptors (HEK/ CD4.403/CXCR4). These target cells were cocultured with a CEM T cell line that harbors a single, defective copy of replication-incompetent HIV-1 proviral DNA and that expresses Env (8.E5 cells). The parental CEM cell line was used as a negative control. This model allowed us to study target cells that do not express wild-type CXCR4. Models 1 and 2 were also created to easily analyze autophagy in the target cells since adherent cells were cocultured with suspension cells.

In model 3 , the target cells were uninfected $\mathrm{CD}^{+} \mathrm{T}$ lymphocytes and the effector cells were CEM T cells infected with the HIV-1 NL4-3 strain $\left(\mathrm{HIV}_{\mathrm{NL4}-3}\right)$. Uninfected CEM cells were used as a negative control. In this model, both target and effector cells were grown in suspension. In order to distinguish the 2 populations, the effector cells were stained with CMFDA, a nontoxic green fluorescent dye (54). Azidothymidine (AZT; $1 \mu \mathrm{M}$ ) was added to the coculture to inhibit viral replication. This model mimics the contact between infected $\mathrm{CD}^{+} \mathrm{T}$ cells and uninfected naive $\mathrm{CD} 4^{+} \mathrm{T}$ cells that mainly occurs in lymph nodes.

Expression patterns of Env on the effector cells and of CD4 and CXCR4 on the target cells are shown in Figure 1.

Env expressed on cells triggers autophagy in uninfected naive $C D 4^{+} \mathrm{T}$ cells. Autophagy was first analyzed in target UC blood $\mathrm{CD}^{+} \mathrm{T}$ lymphocytes after coculture with HEK or HEK.Env (model 1 ). In the cytoplasm of a significant number of $\mathrm{UC}$ blood $\mathrm{CD}^{+} \mathrm{T}$ cells cocultured for 3 days with HEK. Env, we observed by transmission electron microscopy (TEM) numerous membrane-bound vacuoles characteristic of autophagosomes that were not present when the $\mathrm{CD}^{+} \mathrm{T}$ cells were cocultured with parental HEK cells (Figure 2A). Rapamycin (Rapa), a classical inducer of autophagy, triggered formation of vacuoles in $\mathrm{UC}$ blood $\mathrm{CD}^{+} \mathrm{T}$ cells, indicating that these $\mathrm{T}$ cells are susceptible to autophagy. Next, to demonstrate that HIV-infected $\mathrm{T}$ cells are also able to induce autophagy in naive UC blood $\mathrm{CD}^{+}$ $\mathrm{T}$ cells, we analyzed the appearance of autophagosomes after $\mathrm{T}$ cell transfection with the reliable autophagosome marker LC3 fused to GFP (GFP-LC3) using model 3. By fluorescence microscopy, 
A

Model 1
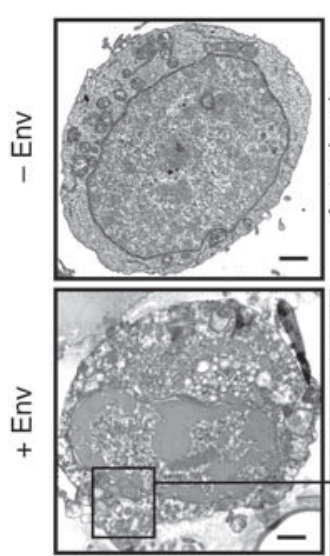

B

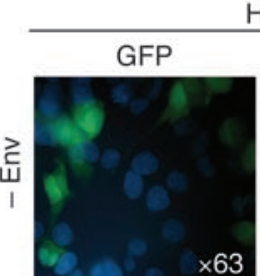

HEK/CD4.403/CXCR4
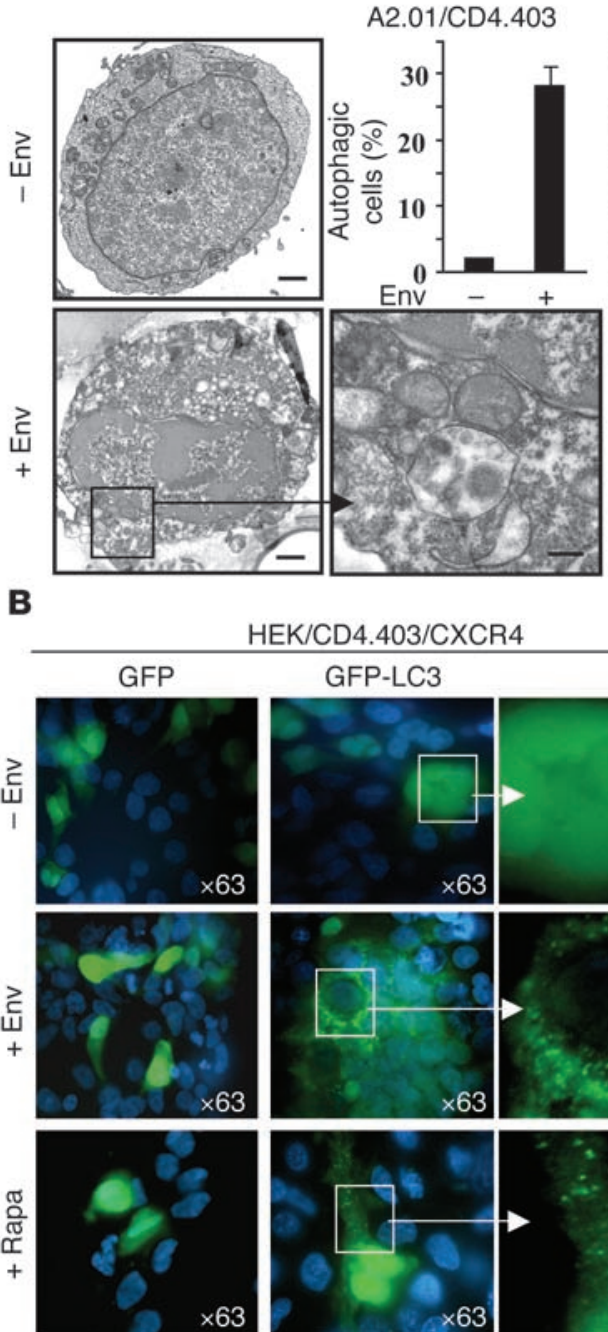

C
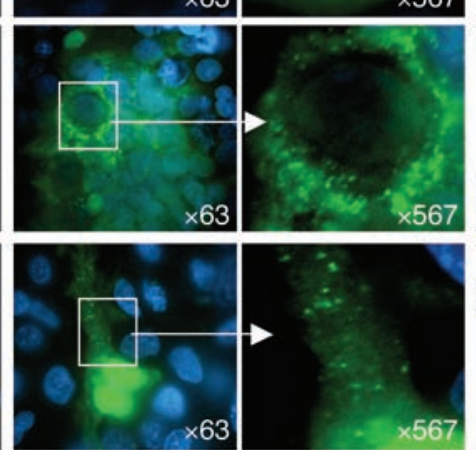

A2.01/

CD4.403

Beclin 1

Actin
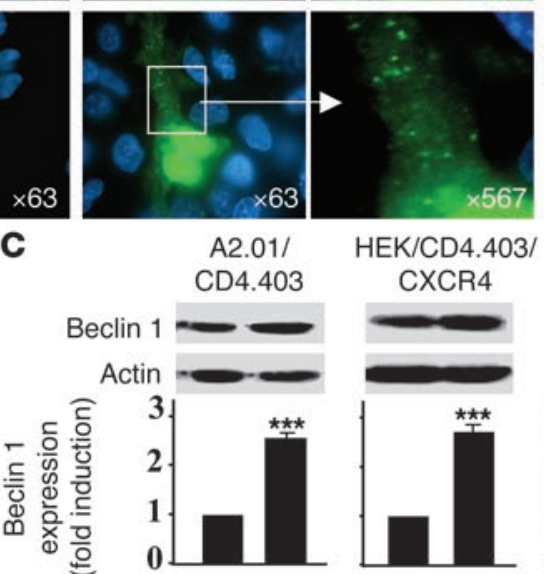

Model 2

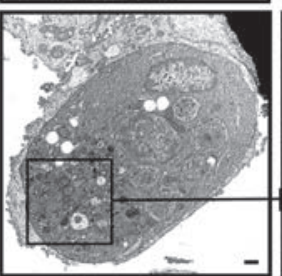

Model 2

HEK/CD4.403/
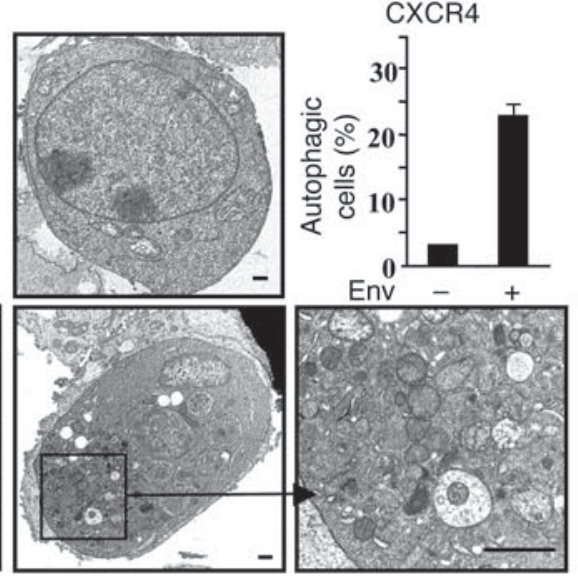

HEK/CD4.403
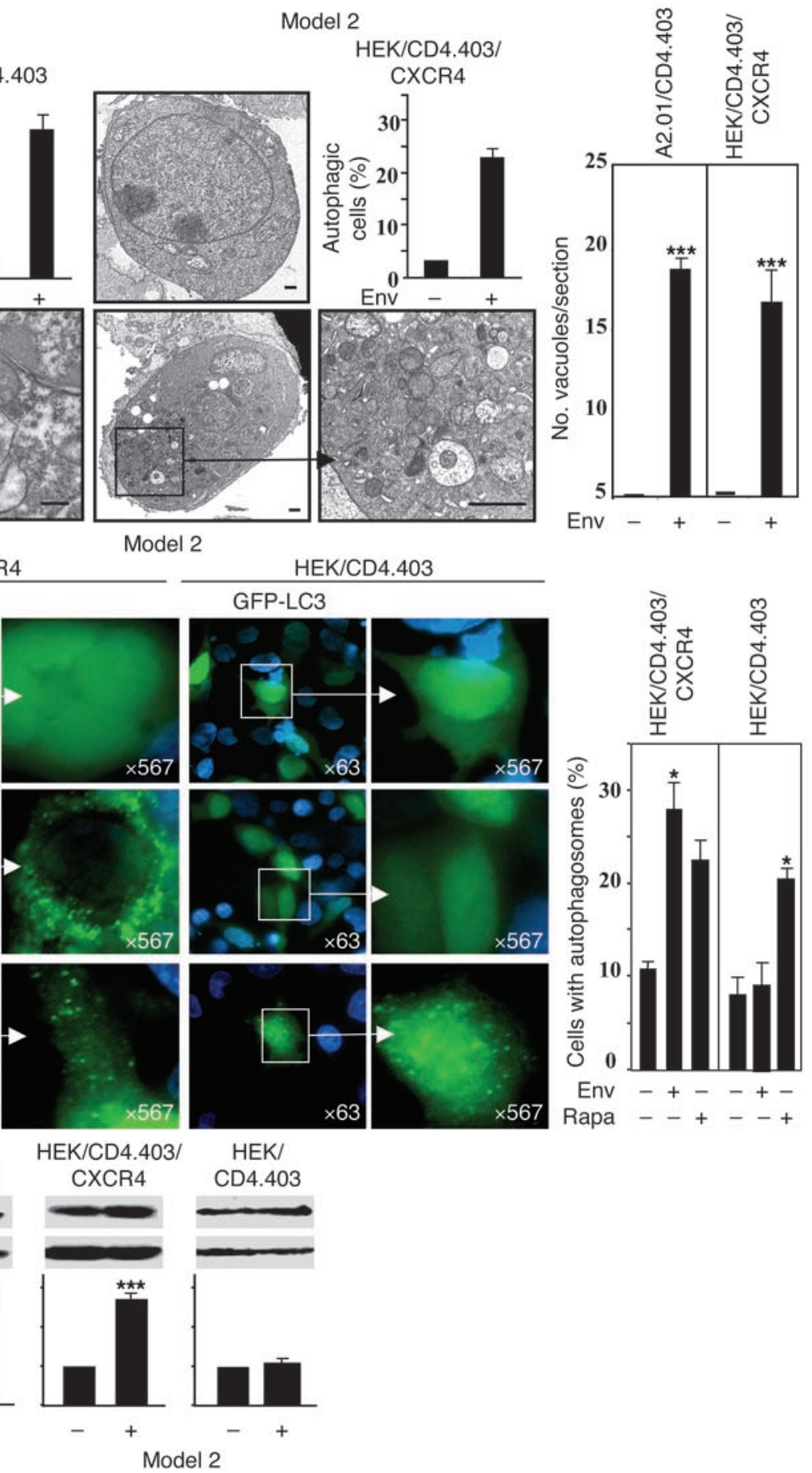

Figure 3

Autophagy is triggered by Env binding to CXCR4. (A) A2.01/CD4.403 and HEK/CD4.403/CXCR4 cells were cocultured for 3 days with cells that do or do not express Env and analyzed by TEM as indicated in Figure 2. Scale bar: $1 \mu \mathrm{m} ; 250 \mathrm{~nm}$ (indicated enlargements). (B) Target HEK/CD4.403/ CXCR4 and HEK/CD4.403 cells were transfected with GFP or GFP-LC3 using the FuGENE 6 Transfection Reagent and cocultured for 3 days with effector cells with or without Env expression or treated with $1 \mu \mathrm{M}$ Rapa. Adherent cells were then examined by epifluorescence. Data are representative of 3 independent experiments and more than 100 cells were counted by 2 investigators. Magnification shown. (C) Immunoblot analysis of Beclin 1 in A2.01/CD4.403, HEK/CD4.403/CXCR4, and HEK/CD4.403 cells cocultured with cells with or without Env expression. ${ }^{\star} P<0.05 ;{ }^{* \star \star} P<0.001$.

punctate staining was observed in the cytoplasm of GFP-LC3transfected UC blood $\mathrm{CD}^{+}{ }^{+} \mathrm{T}$ cells cocultured with $\mathrm{HIV}_{\mathrm{NL4}-3^{-}}$ infected CEM cells, while only a diffuse pattern was obtained in
GFP-LC3-transfected CD4 ${ }^{+} \mathrm{T}$ cells cocultured with uninfected CEM cells (Figure 2B). Punctate LC3 staining was also observed in GFP-LC3-transfected UC blood $\mathrm{CD}^{+} \mathrm{T}$ cells cocultured with 
A

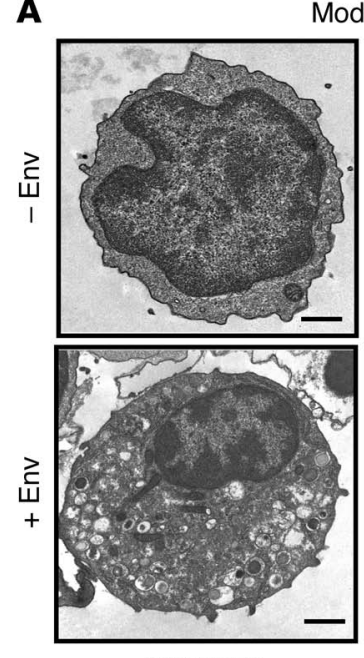

Model 1

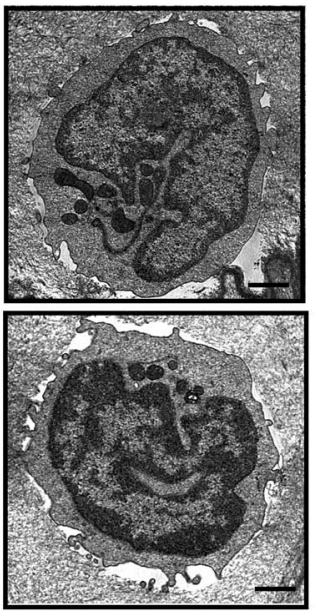

+ AMD3100

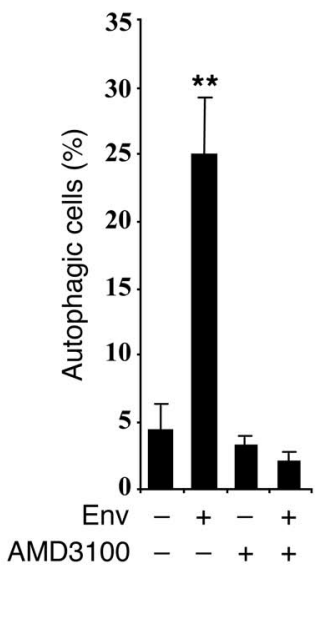

B

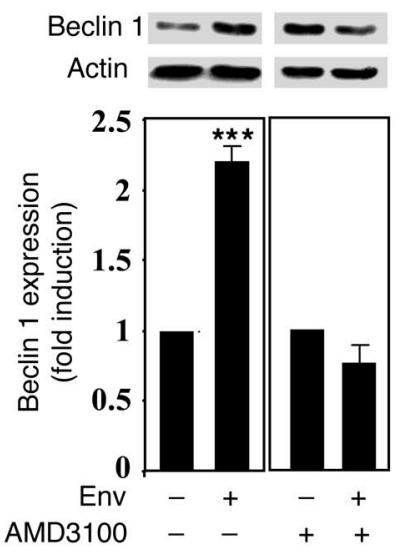

\section{Figure 4}

AMD3100 inhibits Env-induced autophagy. (A) UC blood CD4+ T lymphocytes were cocultured for 3 days with HEK cells that do or do not stably express Env in the presence or absence of AMD3100 (1 $\mu \mathrm{g} / \mathrm{ml})$ and examined by TEM as previously described. Scale bars: $1 \mu \mathrm{m}$. (B) Immunoblot analysis of Beclin 1 in CD4+ $\mathrm{T}$ cells cocultured for 3 days with cells with or without Env expression in the presence or absence of $1 \mu \mathrm{g} / \mathrm{ml}$ AMD3100. ${ }^{* \star} P<0.01 ;{ }^{* \star} P<0.001$.

HEK.Env (model 1; data not shown). No punctate staining was observed in UC blood CD4 ${ }^{+} \mathrm{T}$ cells transfected with GFP-LC3 and cocultured with HEK (model 1; data not shown) or in UC blood $\mathrm{CD}^{+} \mathrm{T}$ cells transfected with GFP and cocultured with effector cells in models 1 and 3 (data not shown).

Expression of Beclin 1 in UC blood $\mathrm{CD}^{+} \mathrm{T}$ cells during the coculture with cells with or without Env expression (model 1) was also analyzed. Beclin 1 accumulated in UC blood CD4 ${ }^{+} \mathrm{T}$ cells within 24 hours of coculture with HEK.Env, and its accumulation was maintained during the 3 days of coculture (Figure 2C). On the contrary, Beclin 1 was not accumulated in $\mathrm{UC}$ blood $\mathrm{CD}^{+} \mathrm{T}$ cells cocultured with HEK. It is worth noting that Rapa at $200 \mathrm{nM}$ or $1 \mu \mathrm{M}$ did not induce Beclin 1 accumulation in $\mathrm{CD}^{+} \mathrm{T}$ cells (data not shown). Thus, contact of X4 Env with HIV receptors, CD4 and CXCR4, on uninfected $\mathrm{CD}^{+} \mathrm{T}$ cells, triggers ultrastructural changes associated with autophagy and accumulation of Beclin 1.

Autophagy is triggered by Env binding to CXCR4. Interaction of X4 Env with its receptors at the $\mathrm{T}$ cell surface is a 2 -step event. First, gp120 binds to CD4, leading to an increased exposure of the gp120 V3 loop and CD4i region which can then interact with CXCR4. Both CD4 and CXCR4 receptors initiate intracellular signaling events after Env binding, including activation and apoptotic signals $(9,55)$. To determine the role of these receptors in the induction of autophagy, we cocultured effector cells with or without Env expression for 3 days with either the A2.01/CD4.403 T cell line or HEK/CD4.403/ CXCR4 cells (models 1 and 2, respectively). It is worth noting that these target cells are susceptible to Env-induced apoptosis $(9,56)$. By TEM, autophagic vacuoles were observed in A2.01/CD4.403 and HEK/CD4.403/CXCR4 cocultured with effector cells expressing Env (models 1 and 2, respectively), while no vacuoles were present in these target cells cocultured with effector cells that did not express Env (Figure 3A). Target CEM cells that expressed wild-type CXCR4 and CD4, as UC blood CD4+ $\mathrm{T}$ cells, were still susceptible to Envmediated autophagy (model 1 , data not shown), indicating that CD4 signaling does not prevent the triggering of autophagy.
Punctate staining was observed in the cytoplasm of GFP-LC3transfected HEK/CD4.403/CXCR4 cocultured with 8 .E5 cells, while only a diffuse pattern was obtained in cells cocultured with effector CEM cells and target cells expressing GFP alone. Furthermore, no formation of autophagosomes was observed in HEK/ CD4.403 that did not express CXCR4 after coculture with effector cells expressing Env (model 2; Figure 3B), indicating that the presence of CXCR4 is necessary for Env-mediated autophagosome formation. The number of target cells with autophagosomes after contact with effector cells that express Env was similar to those obtained after incubation with $1 \mu \mathrm{M}$ Rapa (Figure 3B). As observed in $\mathrm{UC}$ blood $\mathrm{CD}^{+} \mathrm{T}$ cells, Beclin 1 was accumulated in target cells that expressed CXCR4 and CD4.403 after coculture for 3 days with effector cells expressing Env. In the same conditions, the level of Beclin 1 expression was stable in target cells that expressed CD4.403 but not CXCR4 (Figure 3C). Time-course experiments were performed to analyze the kinetics of the autophagic process induced by Env or Rapa in HEK/CD4.403/CXCR4 cells. LC3 punctate staining was significantly induced after 2 days of coculture with 8.E5 cells, and the level of autophagy was maintained after 3 days of coculture with these effector cells. Rapa induced slightly different kinetics, since the number of cells with autophagosomes decreased on the third day of incubation (Supplemental Figure 1A; supplemental material available online with this article; doi:10.1172/JCI26185DS1).

The finding that cell-expressed Env induced formation of autophagic vacuoles in 2 target cell types expressing wild-type CXCR4 and a truncated form of CD4 but not in cells that did not express CXCR4 indicates that Env-mediated autophagy is not cell type dependent and that activation of signaling pathways through CD4 is not needed.

Expression of Beclin 1 was studied in target A2.01/CD4.403, HEK/CD4.403/CXCR4, and HEK/CD4.403 cells after coculture with effector cells with or without Env expression for 1-3 days (models 1 and 2). Accumulation of Beclin 1 was observed in cells 
A
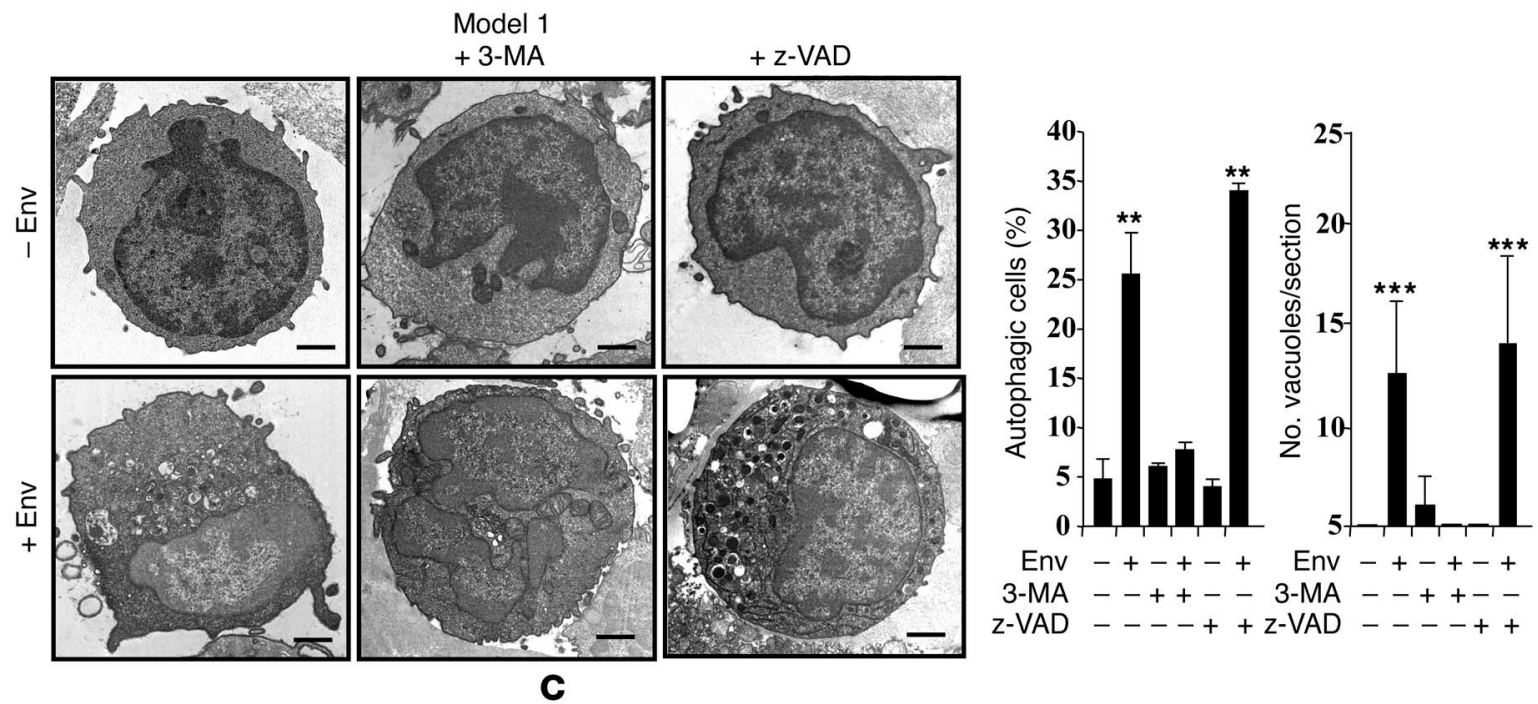

B
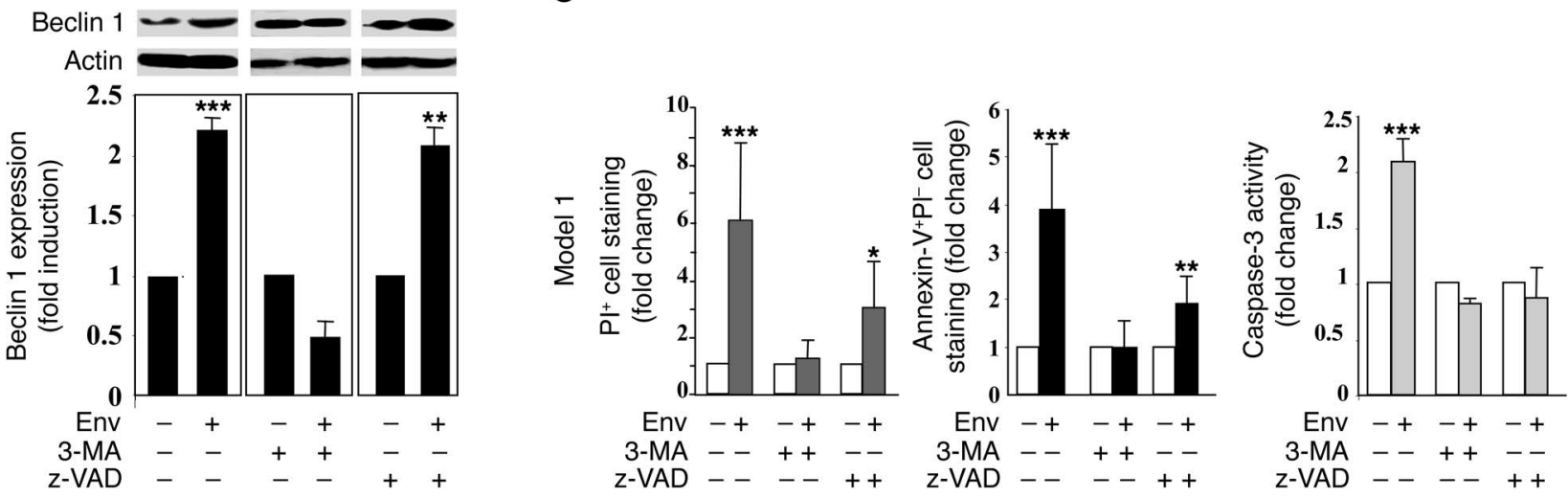

Figure 5

Env expressed on adherent effector cells triggers caspase-dependent and -independent cell death pathways in uninfected CD4+ $T$ cells that are blocked by 3-MA. (A) UC blood CD4+ T lymphocytes were cocultured for 3 days with HEK or HEK.Env in the presence or absence of 10 mM 3-MA and $50 \mu \mathrm{M}$ z-VAD. Cells were examined by TEM as previously described. Scale bars: $1 \mu \mathrm{m}$. (B) Beclin 1 expression was analyzed in CD4+ T lymphocytes cocultured for 3 days with cells with or without Env expression in the presence or absence of 3-MA and z-VAD. (C) Fold increase in Env-mediated CD4+ T cell death was analyzed by PI cell staining (global cell death), Annexin-V and PI cell staining (non necrotic cell death) and caspase-3 activity (apoptosis) in the presence or absence of 3-MA and z-VAD. The fold change of cell staining or caspase-3 activity was calculated as the percentage of positive target cells after coculture with cells that express Env versus those that do not express Env. Results are from at least 5 independent experiments. ${ }^{\star} P<0.05$; ${ }^{* \star} P<0.01$; ${ }^{* \star *} P<0.001$.

expressing CD4.403 and CXCR4 as early as the first day of coculture with effector cells expressing Env, and this accumulation was maintained during the 3 days of coculture. On the contrary, no accumulation of Beclin 1 occurred in cells that did not express CXCR4 (Supplemental Figure 1B). Thus, Env-induced Beclin 1 accumulation is dependent on the presence of CXCR 4 on the target cells and precedes autophagosome formation.

Furthermore, AMD3100, a small-molecule inhibitor of HIV-1 entry via the CXCR4 coreceptor (57) that efficiently blocks Envinduced apoptosis (58), was able to inhibit autophagic vacuole formation (Figure 4A) and Beclin 1 accumulation (model 1; Figure 4B) after contact with Env. It is worth noting that SDF-1, the physiological CXCR4 ligand, was alone unable to trigger autophagy (data not shown). In addition, suramin, which binds to the V3 loop of HIV-1 gp120 (59) and inhibits Env-induced apoptosis (56), blocked autophagosome formation as visualized by fluorescence studies after GFP-LC3 transfection (model 2; Supplemental Figure 2).
This result highlights the role played by gp120 binding on CXCR4 to trigger autophagy. Furthermore, these are the first data to our knowledge to demonstrate that a chemokine receptor engagement is able to trigger autophagy.

Interconnection between Env-induced autophagy and apoptosis. Env expressed on cells is able to activate apoptosis $(9,10,60)$ and autophagy (our present results) after binding to CXCR4 on target cells. We then investigated whether these cell death-associated phenomena are linked as well as the role of the autophagic process in Env-mediated T cell death. To answer these questions, we used inhibitors for each pathway. The drug 3-methyladenine (3-MA) is widely used as an inhibitor of autophagy since it was found to prevent autophagosome formation without markedly affecting protein synthesis or ATP levels (61). At the sequestration step, 3-MA interferes with the activity of class III PI3K to interrupt autophagy $(40,62)$. To inhibit apoptosis, z-Val-Ala-Asp (OMe)- $\mathrm{CH}_{2} \mathrm{~F}$ (z-VAD), a pan-caspase inhibitor, was used. The percentage of UC blood $\mathrm{CD} 4^{+} \mathrm{T}$ cells accumulating autophagic vacuoles after coculture for 
A
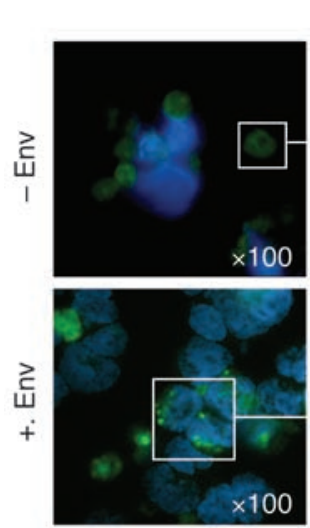

$\times 100$
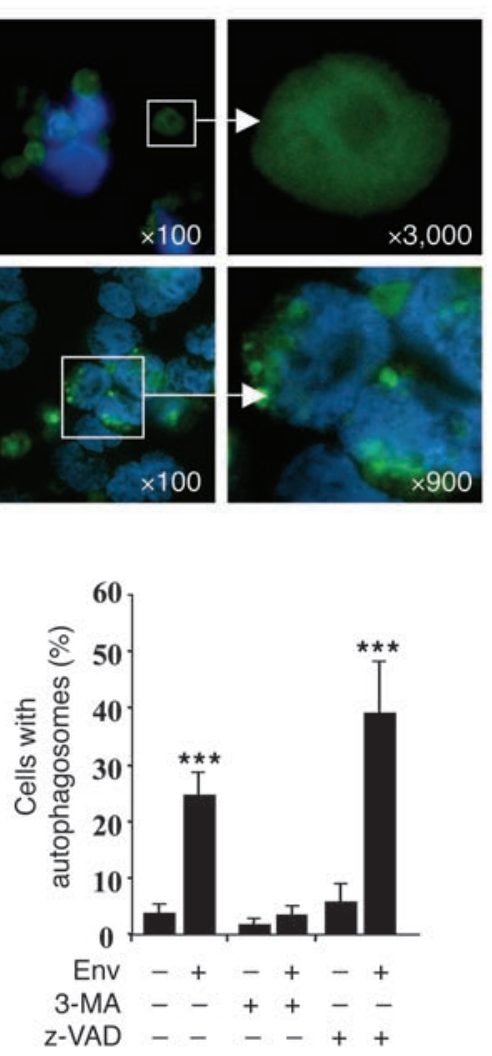

Model 3
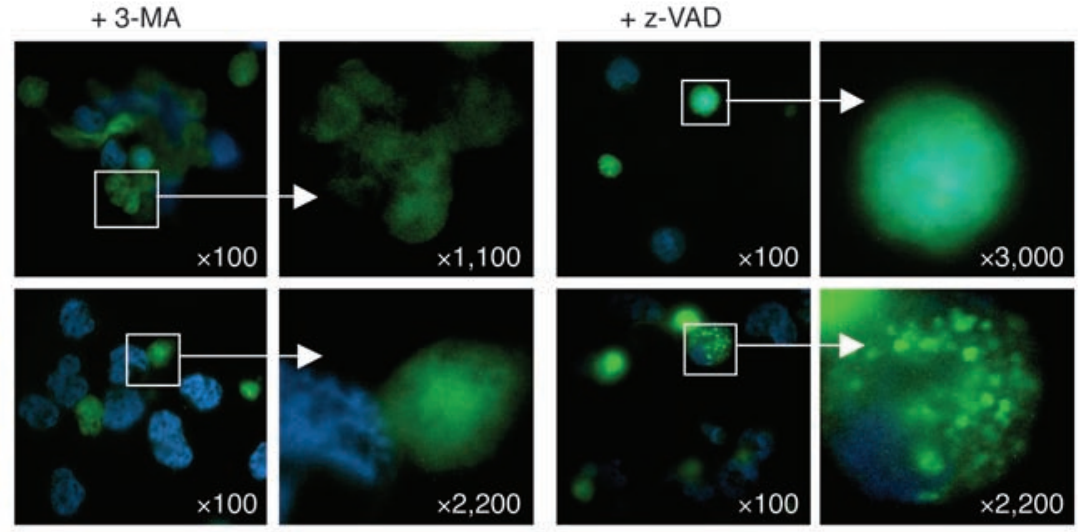

B
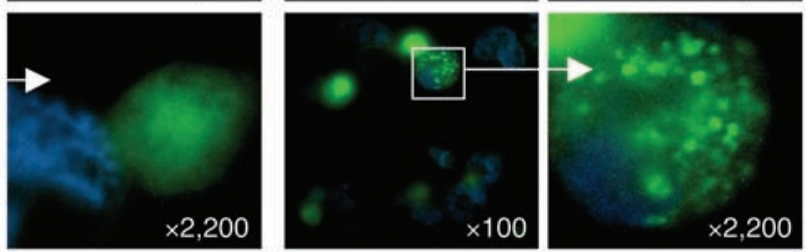

Model 3
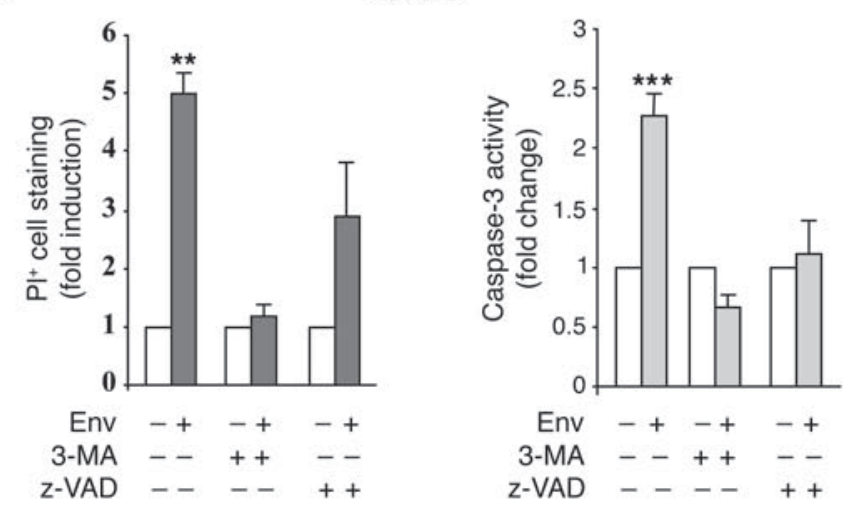

Figure 6

Env expressed on infected effector $\mathrm{CD} 4^{+} \mathrm{T}$ cells triggers caspase-dependent and -independent cell death pathways in uninfected CD4 ${ }^{+} \mathrm{T}$ cells

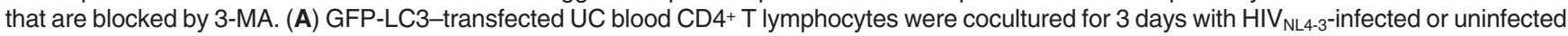
CEM cells in the presence or absence of $10 \mathrm{mM}$ 3-MA or $50 \mu \mathrm{M}$ z-VAD. Cells were examined by fluorescence as described in Figure 2. Magnification shown. (B) Fold increase in Env-mediated uninfected CD4+ T cell death was studied by PI cell staining (global cell death) and caspase-3 activity (apoptosis) in the presence or absence of 3-MA or Z-VAD. Results are from at least 3 independent experiments. ${ }^{* \star} P<0.01 ;{ }^{* \star} P<0.001$.

3 days with effector HEK.Env was strongly reduced in the presence of 3-MA, but no decrease was observed in the presence of $z$-VAD. Furthermore, $z$-VAD did not reduce the number of autophagic vacuoles in the autophagic $\mathrm{CD} 4^{+} \mathrm{T}$ cells after coculture with HEK.Env (model 1; Figure 5A). These results demonstrate that 3-MA, but not $z$-VAD, prevents Env-induced autophagy. Beclin 1 accumulation was also suppressed in $\mathrm{CD} 4^{+} \mathrm{T}$ cells after coculture for 3 days with HEK.Env in the presence of 3-MA but not in the presence of $z$-VAD (Figure 5B). Next we studied the level of Env-mediated global cell death by propidium iodide (PI) cell staining and the level of Env-mediated apoptosis by analysis of caspase-3 activity. We also analyzed by flow cytometry the percentage of non-necrotic CD4 ${ }^{+}$ $T$ cells that exposed phosphatidylserine (PS) at their surface (cells stained with Annexin-V but PI negative) after coculture with cells with or without Env expression. This labeling is currently used to detect apoptosis, but PS exposure was also recently observed in the autophagic process (63). Administration of 3-MA totally inhibited Env-mediated global CD4 ${ }^{+} \mathrm{T}$ cell death, caspase- 3 activity, and PS exteriorization (Figure 5C). On the contrary, z-VAD, which totally inhibited apoptosis, did not abolish Env-mediated global $\mathrm{T}$ cell death (Figure 5C). Similar results were obtained using the trypan blue exclusion test (data not shown). This suggests that Env trig- gers both caspase-dependent and -independent cell death pathways and that Env-mediated autophagy is needed to trigger apoptosis.

We also analyzed the capability of these drugs to inhibit autophagy and cell death triggered in uninfected target $\mathrm{CD}^{+} \mathrm{T}$ cells after coculture with effector $\mathrm{HIV}_{\mathrm{NL} 4-3}$-infected $\mathrm{CD}^{+} \mathrm{T}$ cells (model 3). Autophagosome formation in UC blood $\mathrm{CD}^{+}{ }^{+} \mathrm{T}$ cells after coculture with HIV-infected or uninfected CEM cells was analyzed by fluorescence using LC3 staining in the presence or absence of 3-MA and $z$-VAD. Punctate LC3 staining was only observed in UC blood $\mathrm{CD}^{+} \mathrm{T}$ cells after coculture for 4 days with infected effector cells. Autophagosome formation was still observed in the presence of z-VAD, but was totally blocked by 3-MA (Figure 6A). Next, death of target $\mathrm{CD}^{+} \mathrm{T}$ cells was analyzed, after coculture with effector CEM cells infected with HIV $_{\text {NL4-3 }}$ or uninfected, by flow cytometry after PI staining. In the same conditions, Env-induced apoptosis was studied by analysis of caspase- 3 activity. Prior to the coculture, uninfected and $\mathrm{HIV}_{\mathrm{NL4}-3}$-infected effector CEM cells were labeled with the nontoxic green fluorescent dye CMFDA to differentiate the target cells. Furthermore, AZT was added to the medium to avoid HIV-1 replication. While 3-MA totally inhibited Env-mediated cell death and caspase- 3 activity, z-VAD did not totally block cell death but completely inhibited apoptosis (Figure 6B). 
A
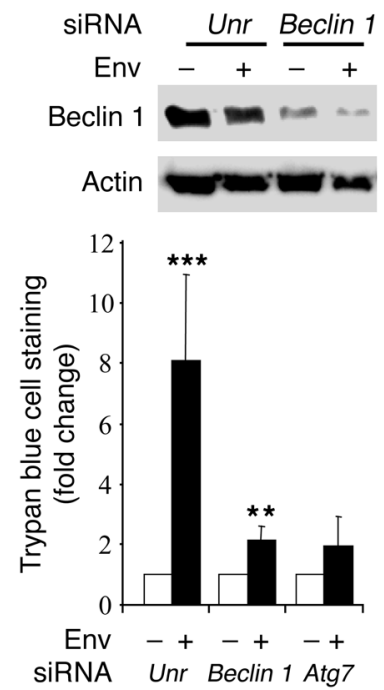

B
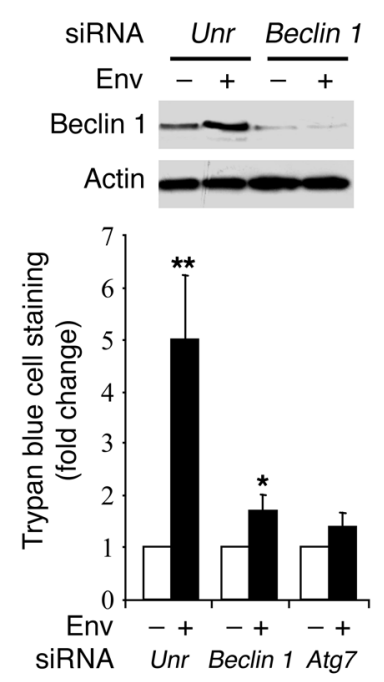

Model 1
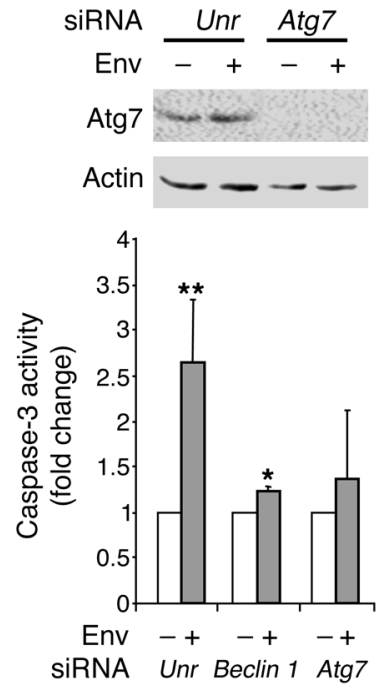

Model 2

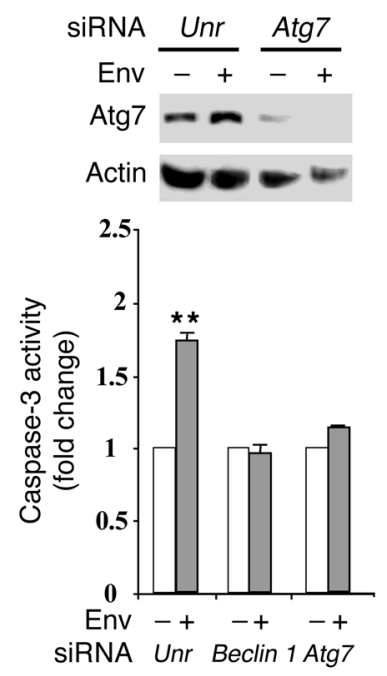

For further confirmation of the involvement of an autophagic process in Env-induced apoptosis, we used gene silencing with siRNA to inhibit expression of 2 genes, Beclin 1/Atg6 and Atg7, related to the autophagic pathway in $\mathrm{CD}^{+}{ }^{+} \mathrm{T}$ cells (model 1; Figure 7A) and in HEK/CD4.403/CXCR4 cells (model 2; Figure 7B). Reduced expression of these 2 proteins by RNA interference induced a dramatic decrease in Env-induced caspase-3 activity and totally inhibited Env-mediated global cell death (Figure 7).

Finally, to determine the role of vacuolization in Env-mediated cell death, we used bafilomycin A1 (Baf A1), an inhibitor of vacuolar $\mathrm{H}^{+}$ATPase $(64,65)$ that leads to accumulation of autophagic vacuoles by blocking their fusion with lysosomes. Baf A1 inhibited global cell death and caspase- 3 activity in uninfected $\mathrm{CD} 4^{+} \mathrm{T}$ cells cocultured with either Env-transfected (model 1) or infected cells (model 3; Figure 8), indicating that vacuolization is not directly responsible for the Env-mediated cell death related to autophagic genes; rather, the complete autophagic process is needed.

Collectively, these data led us to propose a model in which autophagy is a prerequisite for Env-induced activation of the apoptotic pathway through CXCR4 (Figure 9).

\section{Figure 7}

siRNAs against Beclin 1 and Atg7 inhibit Env-mediated cell death. (A) $\mathrm{CD}^{+} \mathrm{T}$ cells were cocultured with cells with or without Env expression after transfection with Beclin 1, Atg7, or unrelated (unr) siRNA. Reduction in expression of the corresponding proteins was analyzed by Western blot using the specific Abs. Global cell death - as determined by trypan blue exclusion test and caspase-3 activity, analyzed by colorimetric assay - is shown. Data are representative of at least 5 independent experiments. (B) HEK/CD4.403/CXCR4 cells were cocultured with cells with or without Env expression after transfection with Beclin 1, Atg7, or unrelated siRNA. Analysis of global cell death and caspase-3 activity was performed as in $\mathbf{A} .{ }^{\star} P<0.05 ;{ }^{*} P<0.01$; ${ }^{* \star} P<0.001$.

\section{Discussion}

The apoptosis of uninfected target $\mathrm{CD} 4^{+} \mathrm{T}$ cells can be induced by the binding of their CXCR4 receptor to Env expressed on effector cells $(9,10,60,66)$. This Env-mediated apoptotic pathway has been proposed as a phenomenon contributing to $\mathrm{CD}^{+}$ $\mathrm{T}$ cell loss during HIV infection. We demonstrate here that cells that expressed Env were also capable of inducing autophagy in uninfected $\mathrm{CD}^{+} \mathrm{T}$ cells. This was equally true of Env-transfected adherent cells, which mimic infected cells of the epithelia, and infected CD4 ${ }^{+} \mathrm{T}$ cells. The autophagic process is triggered by Env binding to CXCR4, since target cells that expressed wild-type CXCR4 and a truncated, signal transduction-incompetent form of CD4 still underwent Env-mediated autophagy, while cells that expressed a truncated form of CD4 but did not express CXCR4, did not. In addition, AMD3100, a CXCR4 antagonist that prevents X4 HIV entry and totally inhibits Env-induced apoptosis, also blocked Env-mediated autophagy. Inhibition of Env-mediated autophagy by suramin, a compound that binds the gp120 V3 loop, also strongly suggests that binding of gp120 to CXCR4 is responsible for this phenomenon. It is worth noting that after 3 days of coculture with effector cells that expressed Env, autophagosomes were also present in syncytia: multinucleated, giant cells formed after fusion between the 2 types of cells in culture through interaction of Env with CD4 and CXCR4. This underlines the role of these receptors in the triggering of autophagy.

The autophagic protein Beclin 1 was rapidly accumulated in $\mathrm{CD}^{+} \mathrm{T}$ cells cocultured with cells that express Env, and its accumulation was maintained during the 3 days of coculture. In contrast, the formation of autophagosomes was only observed after 2 days of coculture, indicating that Beclin 1 is involved in the very early steps of the Env-induced signaling cascade, preceding autophagic vacuolization. Accumulation of Beclin 1 has also been reported in response to drugs that trigger cell death with autophagic features $(29,35,43)$. However, the precise mechanism of Beclin 1 accumulation is unknown and remains to be investigated.

Interestingly, Env-mediated autophagy not only preceded apoptosis but was also required for this process. Indeed, the inhibition of Env-induced autophagy by either administration of general inhibitors of autophagy (3-MA and Baf A1) or inhibition of 2 genes involved in the autophagic pathway (Beclin 1 and Atg7) inhibited caspase- 3 cleavage as well as activity, which mainly occurs in $\mathrm{CD}^{+}$ T cells after 3 days of coculture with cells expressing Env (9). These results corroborate several studies that have already demonstrated that autophagy can be required for apoptosis (67-72). It should be pointed out, however, that if the initial phase of autophagy is required, it is not necessarily sufficient for triggering apoptosis (69). In our study, Baf A1, which is known to block the formation 


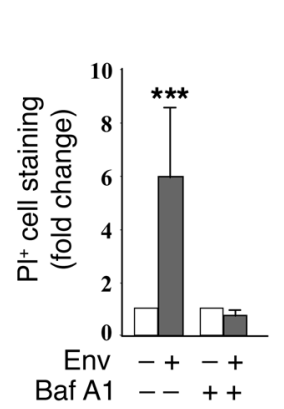

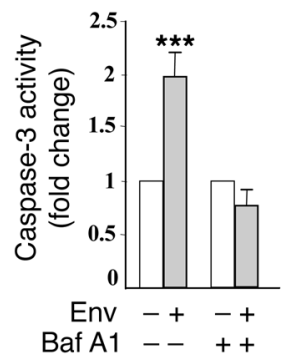

Model 3
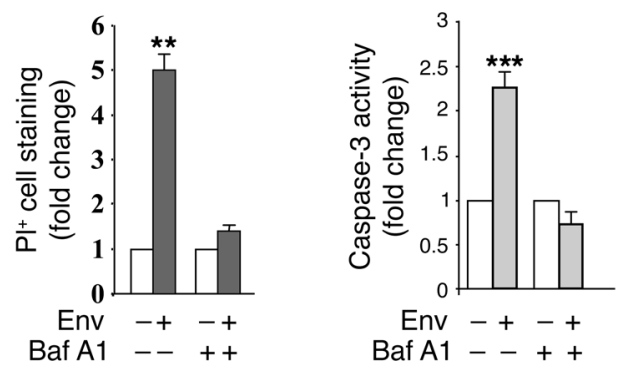

of autophagolysosomes, totally inhibited Env-mediated apoptosis, indicating that the complete autophagic process is needed for this apoptotic pathway. This also suggests that even if autophagic vacuole formation alone does not induce apoptotic cell death, lysosomal degradation of the autophagic vacuole contents does.

In addition, inhibition of autophagy totally blocked Envinduced $\mathrm{T}$ cell death, whereas inhibition of Env-mediated apoptosis did not. Even if these data were obtained in nonphysiological conditions, i.e., when apoptosis was blocked, they indicate that Env induces a nonapoptotic cell death with autophagic features. This corroborates recent data indicating that PCD dependent on autophagy genes can directly contribute to cell death $(29,38,73)$. In Dictyostelium, a nonvacuolar cell death pathway was observed in the presence of conspicuous vacuolization (74). It is worth noting that Baf A1 decreased cell viability independently of Env signaling, indicating that accumulation of vacuoles may lead to a basal level of cell death without triggering the specific cascade of events through interaction of Env with CXCR4.

Together, these results demonstrate that autophagy and apoptosis are responsible for $\mathrm{CD}_{4}^{+} \mathrm{T}$ cell destruction during HIV infection but also raise unsolved questions about the mechanisms by which these cellular death pathways are triggered after Env binding to CXCR4. One hypothesis may be that Beclin 1, which was first identified as a Bcl-2-interacting protein and accumulates during the Env-mediated autophagic process, could enhance caspase- 9 activity by interacting with $\mathrm{Bcl}-2$ and $\mathrm{Bcl}-\mathrm{x}_{\mathrm{L}}$ antiapoptotic proteins, as recently demonstrated in human gastric cancer cells after cis-diamminedichloroplatinum-induced apoptosis (35). This hypothesis certainly needs to be tested, since caspase- 9 is cleaved during Env-mediated apoptosis, which was shown here to be activated by the autophagic process. Very recently, Pattingre et al. demonstrated that Bcl-2 antiapoptotic proteins inhibit Beclin 1dependent autophagy (28). Env-mediated accumulation of Beclin 1 may thus disrupt this equilibrium to trigger the cell toward both autophagy and apoptosis. Indeed, as demonstrated in yeast (75), cell death can also be considered to be a complex cellular response

\section{Figure 8}

Baf A1 inhibits global CD4+ $\mathrm{T}$ cell death and apoptosis. (A) Analysis of CD4 ${ }^{+} \mathrm{T}$ cell death after coculture with HEK and HEK.Env, as described in Figure 5, in the presence or absence of $100 \mathrm{nM}$ Baf A1. (B) Analysis of $\mathrm{CD} 4^{+} \mathrm{T}$ cell death after coculture with $\mathrm{HIV}_{\mathrm{NL4-3}}$-infected or uninfected $\mathrm{CD}^{+} \mathrm{T}$ cells, as described in Figure 6 , in the presence or absence of $100 \mathrm{nM}$ Baf $\mathrm{A} 1 .{ }^{* \star} P<0.01 ;{ }^{* \star} P<0.001$.

triggered by mitochondrial dysfunction rather than by one specific cell death pathway. In line with this, Env binding to CXCR4 activates the intrinsic pathway of apoptosis, in which mitochondria play a central role. Moreover, there is now considerable evidence that mitochondria integrate a plethora of cell death signals (76).

We do not currently know whether Env-induced autophagy was first triggered to rescue the $\mathrm{CD} 4^{+} \mathrm{T}$ cells from cell death or if the autophagic process is directly activated to kill the $\mathrm{CD}^{+}$ uninfected T lymphocytes. One hypothesis is that Env-mediated autophagy may reduce the mass of cells prior to apoptosis, facilitating their phagocytosis. However, once activated, the ultimate consequence of autophagy is the triggering of cell death that contributes to pathology. Very recently, in an autosomal-dominant familial neurohypophyseal diabetes insipidus, autophagymediated cell death was proposed as a "2-hit" process, in which autophagy is first prosurvival after a cellular stress by removing potentially toxic aggregates, but this ongoing autophagic activity sensitizes cells to the toxic effects of a second insult (77). Exclusive definitions of each PCD may be artificial due to the overlap and shared signaling pathways among these different cell death programs (78), perhaps due to redundant cell death mechanisms. Indeed, Golstein and Kroemer have made the hypothesis that autophagic or apoptotic elements might have been added to a primordial death mechanism, initially improving cell dismantling and later acquiring the ability to act by their own right as death effectors (79).
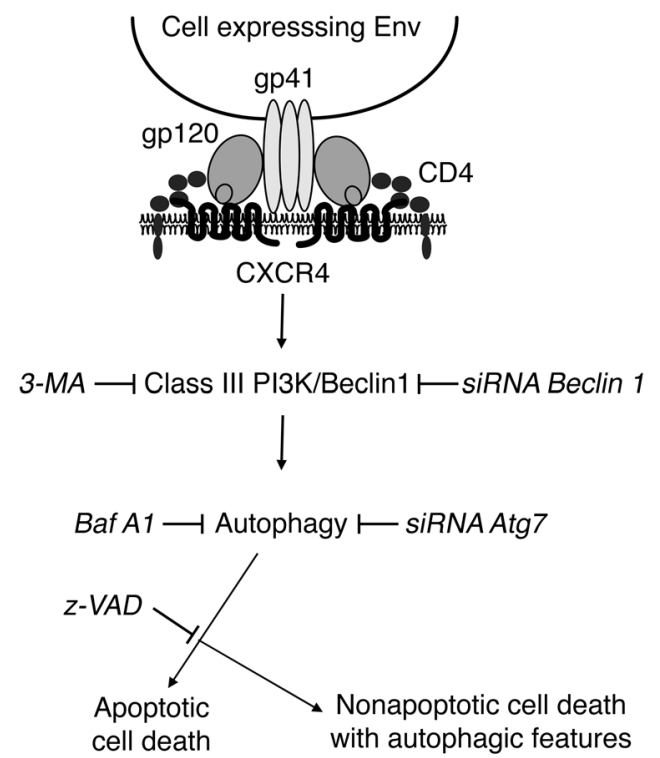

\section{Figure 9}

A model for Env-induced signaling cell death cascade. Autophagy is specifically triggered after Env binding to CXCR4, leading to apoptosis. Nonapoptotic cell death with autophagic features is observed when apoptosis is blocked. 
Another unsolved question concerns the fact that other signaling pathways coming from molecules that participate in the virological synapse formation may be necessary, in addition to the interaction between Env and CXCR4. Nothing is currently known about autophagy induced in uninfected $\mathrm{CD} 4^{+} \mathrm{T}$ cells by free virions and in $\mathrm{HIV}$-infected $\mathrm{CD} 4^{+} \mathrm{T}$ cells, and there is no direct demonstration of the presence of autophagic T cells in vivo in HIV-infected patients. Further investigation will be required to answer these points.

To the best of our knowledge, these findings represent the first example of autophagy triggered through binding of virus envelope proteins to a cellular receptor without viral replication, leading to apoptosis and cell death linked to autophagy.

This study suggests that naive $\mathrm{CD} 4^{+} \mathrm{T}$ cells, which cannot be productively infected by HIV, may take different routes to die after contact with a cell infected by an X4 HIV strain and that sequential, but not exclusive, cell death pathways are triggered by Env binding to CXCR4. Autophagy thus plays a crucial role in Env-mediated CD4 ${ }^{+}$ $\mathrm{T}$ cell death that leads to the physiopathology of AIDS.

\section{Methods}

Cell culture. The original HEK.293 cell line as well as HEK.Env (9), HEK/ CD4.403/CXCR4, and HEK/CD4.403 cells were cultured in DMEM supplemented with $1 \%$ penicillin/streptomycin antibiotic mixture, $1 \%$ Glutamax (Cambrex), and 10\% FCS (Perbio, Fisher Scientific).

The CEM T cell line was provided by the ATCC. The CEM-derived A2.01/ CD4.403 cell clone, which expresses a mutant form of CD4 truncated at position 403 (80) was provided by D.R. Littman (New York Medical College, New York, New York, USA). The 8.E5 cell line, a CEM-derived T cell line containing a single integrated copy of HIV-1 and unable to produce infectious virions, was provided by F. Barré-Sinoussi (Institut Pasteur, Paris, France). These T cell lines were cultured in RPMI 1640 medium supplemented with $1 \%$ penicillin/streptomycin, $1 \%$ Glutamax, and $10 \%$ FCS. UC blood CD4 ${ }^{+} \mathrm{T}$ cells from UC blood samples obtained from caesarean deliveries were purified by negative selection using the Human $\mathrm{CD}^{+} \mathrm{T}$ Cell Enrichment cocktail (StemCell Technologies). UC blood cells were cultured in complete RPMI 1640 medium containing IL-4 (10 ng/ml). Procedures using human cells were approved by the Human Experimentation and Ethics Committee of the CNRS Institute.

Reagents and antibodies. z-VAD was purchased from Calbiochem (Merck); 3-MA was purchased from MP Biomedicals; and AMD3100, Baf A1, and suramin were purchased from Sigma-Aldrich. The anti-Beclin $1 \mathrm{Ab}$ was purchased from tebu-bio. Anti-cleaved caspase- $3 \mathrm{Ab}$ was purchased from Cell Signaling Technology. Rapa was purchased from VWR, and CMFDA was purchased from Invitrogen.

Flow cytometry. Cells $\left(1 \times 10^{5}\right)$ were incubated for 1 hour at $4^{\circ} \mathrm{C}$ with $50 \mu \mathrm{l}$ PBS supplemented - or not - with the appropriate Ab. After washes with $\mathrm{PBS}$, bound $\mathrm{Ab}$ was revealed by addition of $50 \mu \mathrm{l}$ of a 1:100 dilution of FITC-conjugated secondary Ig. After staining for 30 minutes, cells were washed with PBS, and fluorescence intensity at $543 \mathrm{~nm}$ was measured on a COULTER EPICS XL Flow Cytometer (Beckman Coulter).

HIV-1 infection. CEM T cells were infected with the HIV-1 X4 NL4-3 strain. CEM cells $\left(5 \times 10^{6}\right)$ were cocultured with plated HEK. 293 cells previously transfected with $5 \mu \mathrm{g}$ of HIV-1 NL4-3 DNA construct using FuGENE 6 Transfection Reagent (Roche Diagnostics) according to the manufacturer's instructions. Follow-up of CEM infection was done by p24 and Env expression analysis using flow cytometry.

RNA interference. The sense and antisense oligonucleotides specific for Beclin 1 and Atg7 siRNA were synthesized by Eurogentec and annealed according to the manufacturer's instructions. The mRNA sequences to be targeted by Beclin 1 and Atg7 siRNA were 5'-CAGUUUGGCA-
CAAUCAAUA-3' and 5'-GGAGUCACAGCUCUUCCUU-3', respectively. $\mathrm{CD}^{+} \mathrm{T}$ cells were transfected using Nucleofector Technology (amaxa biosystems), according to the manufacturer's instructions, and HEK/ CD4.403/CXCR4 cell transfection was performed using the Oligofectamine reagent (Invitrogen). Transfected cells were then cocultured with cells with or without Env expression.

TEM analysis. After 3 days of coculture with cells with or without Env expression, cells were fixed in situ with $2.5 \%$ glutaraldehyde in cacodylate buffer ( $\mathrm{pH} 7.4$ ) for 60 minutes at $4^{\circ} \mathrm{C}$. Cells were then postfixed with $2 \%$ osmium tetroxide and washed in cacodylate buffer containing $0.5 \%$ tannic acid. After extensive washes in $0.1 \mathrm{M}$ Sorensen phosphate buffer ( $\mathrm{pH}$ 7.2), cells were included in a fibrin clot as described by Charret and Fauré-Fremiet (81). Cells were then postfixed with $2 \%$ osmium tetroxide and $0.5 \%$ tannic acid, dehydrated, and embedded in epon (EMbed-812; Electron Microscopy Sciences). Sections were counterstained with uranyl acetate and lead citrate and examined with a Hitachi H7100 TEM.

Western blot analysis. Cells were washed twice in PBS and lysed in buffer containing $50 \mathrm{mM}$ Tris $\mathrm{HCl}$ ( $\mathrm{pH}$ 8), $1 \%$ Triton X-100, $100 \mathrm{mM} \mathrm{NaCl}$, $1 \mathrm{mM} \mathrm{MgCl}_{2}, 150 \mu \mathrm{M}$ PMSF, and complete mini protease inhibitor cocktail (Roche Diagnostics). Cell lysates were electrophoresed in 10\% SDS-PAGE and blotted to PVDF membranes. After a blocking step for 1 hour at room temperature, blots were incubated overnight at $4^{\circ} \mathrm{C}$ with the primary $\mathrm{Ab}$ in the blocking buffer. After 3 washes with TBS and $0.05 \%$ Tween, the blots were incubated for 1 hour at room temperature with peroxidase-coupled antiserum diluted in TBS, $5 \%$ milk, and $0.05 \%$ Tween. After further washes, the immune complexes were revealed by ECL (PerkinElmer) and autoradiographed. Quantification of protein expression was performed by densitometry analysis of the autoradiograms using Image J (http://rsb.info.nih.gov/ij/). Data were normalized with reference to the density analysis of actin.

Detection of cell death and apoptosis. Cell death of the $\mathrm{CD} 4^{+} \mathrm{T}$ cells was studied after coculture with effector cells with or without Env expression by flow cytometry analysis using PI and Annexin-V-FITC staining. Briefly, suspension cells were washed with PBS, carefully resuspended in $50 \mu \mathrm{l}$ binding buffer (100 mM HEPES, $\mathrm{pH} 7.4 ; 140 \mathrm{mM} \mathrm{NaCl} ; 5 \mathrm{mM} \mathrm{CaCl}_{2}$ ), and a mixture of $4 \mu \mathrm{l}$ Annexin-V-FITC and $4 \mu \mathrm{l}$ PI was added. After incubation for 20 minutes in the dark at $4^{\circ} \mathrm{C}$, cells were analyzed on a COULTER EPICS XL Flow Cytometer (Beckman Coulter). Cell viability was also determined by trypan blue exclusion test. The total number of dead cells was counted and normalized with reference to the total number of cells. Apoptosis was determined using the caspase- 3 colorimetric assay from R\&D Systems according to the manufacturer's instructions.

LC3 staining. HEK/CD4.403/CXCR4 cells were cultured in 6-well plates and transfected with pEGFP or pEGFP-LC3 plasmid (referred to as GFP and GFP-LC3, respectively) using FuGENE 6 Transfection Reagent. UC blood $\mathrm{CD}^{+} \mathrm{T}$ cells were transfected with GFP or GFP-LC3 using the Nucleofector apparatus (amaxa biosystems) according to the manufacturer's instructions. Transfected HEK or $\mathrm{CD} 4^{+} \mathrm{T}$ cells were cocultured with effector cells with or without Env expression for 3 or 4 days, respectively. Target cells were then washed with PBS and fixed in $3.7 \%$ paraformaldehyde in PBS for 10 minutes at room temperature (HEK cells) or in an acetone/methanol (vol/vol) mixture for 10 minutes at $-20^{\circ} \mathrm{C}$ (UC blood $\mathrm{CD}^{+} \mathrm{T}$ cells) and examined by epifluorescence using a Leica microscope. More than 100 transfected cells were counted by 2 investigators. Only cells with at least 5 spots were counted as positive. Results are from at least 3 independent experiments.

CMFDA staining. Cells were incubated for 30 minutes in prewarmed $0 \%$ FCS culture medium containing $20 \mu \mathrm{M}$ CMFDA. After centrifugation, cells were resuspended in fresh prewarmed culture medium without FCS for 30 minutes and washed 3 times. Cell fluorescence was controlled by flow cytometry analysis. 
Statistics. Analysis of the variance of the results obtained after binding to cells that do not express Env versus cells that express Env was performed after arc sine transformation of the data when percentages were compared (82). Differences were considered significant at ${ }^{*} P<0.05$, ${ }^{*} P<0.01$, and ${ }^{* *} P<0.001$.

\section{Acknowledgments}

We thank T. Yoshimori for providing the GFP-LC3 construct and W.A. Dunn for providing anti-Atg7 antibodies and highly useful comments. Thanks are also due to M. Djavaheri-Mergny and L. Briant for providing us with Atg7 and Beclin 1 siRNAs and unrelated siRNA, respectively. We are greatly indebted to B. Vigouroux (CHU Montpellier, Montpellier, France) for providing UC blood. We thank Q. Sattentau and I. Robbins for helpful scientific discussions and careful critical reading of the manuscript. This work was supported by institutional funds from the Centre National de la
Recherche Scientifique (CNRS) and the Montpellier I University (UM1) and grants from SIDACTION and the Agence Nationale de Recherches sur le SIDA (ANRS). L. Espert was the recipient of a fellowship from SIDACTION and ANRS.

Received for publication June 6, 2005, and accepted in revised form May 9, 2006.

Address correspondence to: Martine Biard-Piechaczyk, Laboratoire Infections Rétrovirales et Signalisation Cellulaire, CNRS UMR 5121, Institut de Biologie, 4 Bd Henri IV, 34000 Montpellier, France. Phone: 33-467-60-86-60; Fax: 33-467-60-44-20; E-mail: martine.biard@univ-montp1.fr.

Patrice Codogno's present address is: INSERM U756, Faculté de Pharmacie, Université Paris-Sud, Châtenay-Malabry, France.
1. Maldarelli, F., Sato, H., Berthold, E., Orenstein, J., and Martin, M.A. 1995. Rapid induction of apoptosis by cell-to-cell transmission of human immunodeficiency virus type 1. J. Virol. 69:6457-6465.

2. Corbeil, J., and Richman, D.D. 1995. Productive infection and subsequent interaction of CD4-gp120 at the cellular membrane is required for HIV-induced apoptosis of CD4+ T cells. J. Gen. Virol. 76:681-690.

3. Laurent-Crawford, A.G., et al. 1993. Membrane expression of HIV envelope glycoproteins triggers apoptosis in CD4 cells. AIDS Res. Hum. Retroviruses. 9:761-773.

4. Garcia, E., et al. 2005. HIV-1 trafficking to the dendritic cell-T-cell infectious synapse uses a pathway of tetraspanin sorting to the immunological synapse. Traffic. 6:488-501.

5. Jolly, C., Kashefi, K., Hollinshead, M., and Sattentau, Q.J. 2004. HIV-1 cell to cell transfer across an Env-induced, actin-dependent synapse. J. Exp. Med. 199:283-293.

6. Nobile, C., et al. 2005. Covert human immunodeficiency virus replication in dendritic cells and in DCSIGN-expressing cells promotes long-term transmission to lymphocytes. J. Virol. 79:5386-5399.

7. Sivard, P., et al. 2004. HIV-1 infection of Langerhans cells in a reconstructed vaginal mucosa. J. Infect. Dis. 190:227-235.

8. Ferri, K.F., et al. 2000. Apoptosis control in syncytia induced by the HIV type 1-envelope glycoprotein complex. Role of mitochondria and caspases. J. Exp. Med. 192:1081-1092.

9. Roggero, R., et al. 2001. Binding of human immunodeficiency virus type 1 gp 120 to CXCR4 induces mitochondrial transmembrane depolarization and cytochrome c-mediated apoptosis independently of Fas signaling. J. Virol. 75:7637-7650.

10. Blanco, J., et al. 1999. The implication of the chemokine receptor CXCR4 in HIV-1 envelope protein-induced apoptosis is independent of the G protein-mediated signalling. AIDS. 13:909-917.

11. Hazenberg, M.D., et al. 2003. Depletion of naive CD4 T cells by CXCR4-using HIV-1 variants occurs mainly through increased T-cell death and activation. AIDS. 17:1419-1424.

12. Nishimura, Y., et al. 2004. Highly pathogenic SHIVs and SIVs target different CD4+ T cell subsets in rhesus monkeys, explaining their divergent clinical courses. Proc. Natl. Acad. Sci. U. S. A. 101:12324-12329.

13. Bursch, W., Ellinger, A., Gerner, C., Frohwein, U, and Schulte-Hermann, R. 2000. Programmed cell death (PCD). Apoptosis, autophagic PCD, or others? Ann. N. Y. Acad. Sci. 926:1-12.

14. Lockshin, R.A., Osborne, B., and Zakeri, Z. 2000. Cell death in the third millennium. Cell Death Differ. 7:2-7.
15. Clarke, P.G. 1990. Developmental cell death: morphological diversity and multiple mechanisms. Anat. Embryol. (Berl.). 181:195-213.

16. Baehrecke, E.H. 2003. Caspase activation finds fertile ground. Dev. Cell. 4:608-609.

17. Gonzalez-Polo, R.A., et al. 2005. The apoptosis/ autophagy paradox: autophagic vacuolization before apoptotic death. J. Cell Sci. 118:3091-3102.

18. Yoshimori, T. 2004. Autophagy: a regulated bulk degradation process inside cells. Biochem. Biophys. Res. Commun. 313:453-458.

19. Mizushima, N., Sugita, H., Yoshimori, T., and Ohsumi, Y. 1998. A new protein conjugation system in human. The counterpart of the yeast Apg12p conjugation system essential for autophagy. J. Biol. Chem. 273:33889-33892.

20. Ohsumi, Y. 2001. Molecular dissection of autophagy: two ubiquitin-like systems. Nat. Rev. Mol. Cell Biol. 2:211-216

21. Tanida, I., Ueno, T., and Kominami, E. 2004. LC3 conjugation system in mammalian autophagy. Int. J. Biochem. Cell Biol. 36:2503-2518.

22. Kabeya, Y., et al. 2000. LC3, a mammalian homologue of yeast Apg8p, is localized in autophagosome membranes after processing. EMBO J. 19:5720-5728.

23. Kihara, A., Kabeya, Y., Ohsumi, Y., and Yoshimori, T. 2001. Beclin-phosphatidylinositol 3-kinase complex functions at the trans-Golgi network. $E M B O$ Rep. 2:330-335.

24. Liang, X.H., et al. 1999. Induction of autophagy and inhibition of tumorigenesis by beclin 1. Nature. 402:672-676

25. Kuma, A., et al. 2004. The role of autophagy during the early neonatal starvation period. Nature. 432:1032-1036.

26. Lum, J.J., et al. 2005. Growth factor regulation of autophagy and cell survival in the absence of apoptosis. Cell. 120:237-248.

27. Boya, P., et al. 2005. Inhibition of macroautophagy triggers apoptosis. Mol. Cell. Biol. 25:1025-1040.

28. Pattingre, S., et al. 2005. Bcl-2 antiapoptotic proteins inhibit beclin 1-dependent autophagy. Cell. 122:927-939.

29. Shimizu, S., et al. 2004. Role of Bcl-2 family proteins in a non-apoptotic programmed cell death dependent on autophagy genes. Nat. Cell Biol. 6:1221-1228.

30. Yue, Z., Jin, S., Yang, C., Levine, A.J., and Heintz, N. 2003. Beclin 1, an autophagy gene essential for early embryonic development, is a haploinsufficient tumor suppressor. Proc. Natl. Acad. Sci. U. S. A. 100:15077-15082.

31. Baehrecke, E.H. 2003. Autophagic programmed cell death in Drosophila. Cell Death Differ. 10:940-945.

32. Debnath, J., Baehrecke, E.H., and Kroemer, G. 2005.
Does autophagy contribute to cell death? Autophagy. 1:66-74.

33. Levine, B., and Yuan, J. 2005. Autophagy in cell death: an innocent convict? J. Clin. Invest. 115:2679-2688. doi:10.1172/JCI26390.

34. Lamparska-Przybysz, M., Gajkowska, B., and Motyl, T. 2005. Cathepsins and BID are involved in the molecular switch between apoptosis and autophagy in breast cancer MCF-7 cells exposed to camptothecin. J. Physiol. Pharmacol. 56(Suppl. 3):159-179.

35. Furuya, D., Tsuji, N., Yagihashi, A., and Watanabe, N. 2005. Beclin 1 augmented cis-diamminedichloroplatinum induced apoptosis via enhancing caspase-9 activity. Exp. Cell Res. 307:26-40.

36. Liang, X.H., et al. 1998. Protection against fatal Sindbis virus encephalitis by beclin, a novel Bcl-2interacting protein. J. Virol. 72:8586-8596.

37. Takacs-Vellai, K., et al. 2005. Inactivation of the autophagy gene bec-1 triggers apoptotic cell death in C. elegans. Curr. Biol. 15:1513-1517.

38. Yu, L., et al. 2004. Regulation of an ATG7-beclin 1 program of autophagic cell death by caspase-8. Science. 304:1500-1502.

39. Melendez, A., et al. 2003. Autophagy genes are essential for dauer development and life-span extension in C. elegans. Science. 301:1387-1391.

40. Petiot, A., Ogier-Denis, E., Blommaart, E.F., Meijer, A.J., and Codogno, P. 2000. Distinct classes of phosphatidylinositol 3 '-kinases are involved in signaling pathways that control macroautophagy in HT-29 cells. J. Biol. Chem. 275:992-998.

41. Rusten, T.E., et al. 2004. Programmed autophagy in the Drosophila fat body is induced by ecdysone through regulation of the PI3K pathway. Dev. Cell. 7:179-192.

42. Daido, S., et al. 2004. Pivotal role of the cell death factor BNIP3 in ceramide-induced autophagic cell death in malignant glioma cells. Cancer Res. 64:4286-4293.

43. Scarlatti, F., et al. 2004. Ceramide-mediated macroautophagy involves inhibition of protein kinase $\mathrm{B}$ and up-regulation of beclin 1. J. Biol. Chem. 279:18384-18391.

44. Kirkegaard, K., Taylor, M.P., and Jackson, W.T. 2004. Cellular autophagy: surrender, avoidance and subversion by microorganisms. Nat. Rev. Microbiol. 2:301-314.

45. Prentice, E., Jerome, W.G., Yoshimori, T., Mizushima, N., and Denison, M.R. 2004. Coronavirus replication complex formation utilizes components of cellular autophagy. J. Biol. Chem. 279:10136-10141.

46. Jackson, W.T., et al. 2005. Subversion of cellular autophagosomal machinery by RNA viruses. PLoS Biol. 3:e156.

47. Talloczy, Z., et al. 2002. Regulation of starvationand virus-induced autophagy by the eIF2alpha 
kinase signaling pathway. Proc. Natl. Acad. Sci. U.S. A. 99:190-195.

48. Schlegel, A., Giddings, T.H., Jr., Ladinsky, M.S., and Kirkegaard, K. 1996. Cellular origin and ultrastructure of membranes induced during poliovirus infection. J. Virol. 70:6576-6588.

49. Suhy, D.A., Giddings, T.H., Jr., and Kirkegaard, K. 2000. Remodeling the endoplasmic reticulum by poliovirus infection and by individual viral proteins: an autophagy-like origin for virus-induced vesicles. J. Virol. 74:8953-8965.

50. Levine, B. 2005. Eating oneself and uninvited guests: autophagy-related pathways in cellular defense. Cell. 120:159-162.

51. Paludan, C., et al. 2005. Endogenous MHC class II processing of a viral nuclear antigen after autophagy. Science. 307:593-596.

52. Guillerm, C., Coudronnière, N., Robert-Hebmann, V., and Devaux, C. 1998. Delayed human immunodeficiency virus type 1 -induced apoptosis in cells expressing truncated forms of CD4. J. Virol. 72:1754-1761.

53. Shaw, A.S., et al. 1990. Short related sequences in the cytoplasmic domains of CD4 and CD8 mediate binding to the amino-terminal domain of the p56 $6^{\text {lck }}$ tyrosine protein kinase. Mol. Cell. Biol. 10:1853-1862.

54. Yang, X.P., Gallo, M., Ngan, I., Nocerini, M., and Chen, M.M. 2002. Use of CMFDA and CMTMR fluorescent dyes in FACS-based antibody screening. Biotechniques. 32:678-680, 682

55. Benkirane, M., Jeang, K.-T., and Devaux, C. 1994. The cytoplasmic domain of CD4 plays a critical role during the early stages of HIV infection in T-cells. EMBO J. 13:5559-5569.

56. Biard-Piechaczyk, M., et al. 2000. Caspase-dependent apoptosis of cells expressing the chemokine receptor CXCR4 is induced by cell membrane-associated Human Immunodeficiency Virus type 1 envelope glycoprotein (gp120). Virology. 268:329-344.

57. Donzella, G.A., et al. 1998. AMD3100, a small molecule inhibitor of HIV-1 entry via the CXCR4 coreceptor. Nat. Med. 4:72-77.

58. Blanco, J., et al. 2000. The CXCR4 antagonist AMD3100 efficiently inhibits cell-surface-expressed human immunodeficiency virus type 1 envelope- induced apoptosis. Antimicrob. Agents Chemother. 44:51-56.

59. Fantini, J., et al. 1997. Synthetic soluble analogs of galactosylceramide (GalCer) bind to the V3 domain of HIV-1 gp120 and inhibit HIV-1-induced fusion and entry. J. Biol. Chem. 272:7245-7252.

60. Perfettini, J.L., et al. 2005. Mechanisms of apoptosis induction by the HIV-1 envelope. Cell Death Differ. 12(Suppl. 1):916-923.

61. Seglen, P.O., and Gordon, P.B. 1982. 3-Methyladenine: specific inhibitor of autophagic/lysosomal protein degradation in isolated rat hepatocytes. Proc. Natl. Acad. Sci. U. S. A. 79:1889-1892.

62. Blommaart, E.F., Krause, U., Schellens, J.P., Vreeling-Sindelarova, H., and Meijer, A.J. 1997. The phosphatidylinositol 3-kinase inhibitors wortmannin and LY294002 inhibit autophagy in isolated rat hepatocytes. Eur. J. Biochem. 243:240-246.

63. Lockshin, R.A., and Zakeri, Z. 2004. Apoptosis, autophagy, and more. Int. J. Biochem. Cell Biol. 36:2405-2419.

64. Bowman, E.J., Siebers, A., and Altendorf, K. 1988. Bafilomycins: a class of inhibitors of membrane ATPases from microorganisms, animal cells, and plant cells. Proc. Natl. Acad. Sci. U. S. A. 85:7972-7976.

65. Yamamoto, A., et al. 1998. Bafilomycin A1 prevents maturation of autophagic vacuoles by inhibiting fusion between autophagosomes and lysosomes in rat hepatoma cell line, H-4-II-E cells. Cell Struct. Funct. 23:33-42.

66. Hesselgesser, J., et al. 1998. Neuronal apoptosis induced by HIV- 1 gp120 and the chemokine SDF- $1 \alpha$ is mediated by the chemokine receptor CXCR4 Curr. Biol. 8:595-598.

67. Canu, N., et al. 2005. Role of the autophagic-lysosomal system on low potassium-induced apoptosis in cultured cerebellar granule cells. J. Neurochem. 92:1228-1242.

68. Guimaraes, C.A., Benchimol, M., AmaranteMendes, G.P., and Linden, R. 2003. Alternative programs of cell death in developing retinal tissue. J. Biol. Chem. 278:41938-41946.

69. Jia, L., et al. 1997. Inhibition of autophagy abrogates tumour necrosis factor alpha induced apoptosis in human T-lymphoblastic leukaemic cells. Br. J. Haematol. 98:673-685.
70. Uchiyama, Y. 2001. Autophagic cell death and its execution by lysosomal cathepsins. Arch. Histol. Cytol. 64:233-246.

71. Hoyer-Hansen, M., Bastholm, L., Mathiasen, I.S., Elling, F., and Jaattela, M. 2005. Vitamin D analog EB1089 triggers dramatic lysosomal changes and Beclin 1-mediated autophagic cell death. Cell Death Differ. 12:1297-1309.

72. Xue, L., Fletcher, G.C., and Tolkovsky, A.M. 1999. Autophagy is activated by apoptotic signalling in sympathetic neurons: an alternative mechanism of death execution. Mol. Cell. Neurosci. 14:180-198.

73. Shao, Y., Gao, Z., Marks, P.A., and Jiang, X. 2004. Apoptotic and autophagic cell death induced by histone deacetylase inhibitors. Proc. Natl. Acad. Sci. U. S. A. 101:18030-18035.

74. Kosta, A., et al. 2004. Autophagy gene disruption reveals a non-vacuolar cell death pathway in Dictyostelium. J. Biol. Chem. 279:48404-48409.

75. Priault, M., et al. 2005. Impairing the bioenergetic status and the biogenesis of mitochondria triggers mitophagy in yeast. Cell Death Differ. 12:1613-1621.

76. Bras, M., Queenan, B., and Susin, S.A. 2005. Programmed cell death via mitochondria: different modes of dying. Biochemistry (Mosc.). 70:231-239.

77. Castino, R., Isidoro, C., and Murphy, D. 2005. Autophagy-dependent cell survival and cell death in an autosomal dominant familial neurohypophyseal diabetes insipidus in vitro model. FASEB J. 19:1024-1026.

78. Broker, L.E., Kruyt, F.A., and Giaccone, G. 2005. Cell death independent of caspases: a review. Clin. Cancer Res. 11:3155-3162.

79. Golstein, P., and Kroemer, G. 2005. Redundant cell death mechanisms as relics and backups. Cell Death Differ. 12(Suppl. 2):1490-1496.

80. Bedinger, P., et al. 1988. Internalization of the human immunodeficiency virus does not require the cytoplasmic domain of CD4. Nature. 334:162-165

81. Charret, R., and Fauré-Fremiet, E. 1967. Technique de rassemblement de micro-organismes: préinclusion dans un caillot de fibrine. J. Microsc. 6:1063-1066.

82. Zar, J.H. 1996. Biostatistical analysis. 3rd edition. Prentice Hall. Upper Saddle River, New Jersey, USA. 662 pp. 